\title{
Ventricular hypertrophy and left atrial dilatation persist and are associated with reduced survival after valve replacement for aortic stenosis
}

\author{
Jocelyn M. Beach, BS, ${ }^{\mathrm{a}}$ Tomislav Mihaljevic, MD, ${ }^{\mathrm{b}}$ Jeevanantham Rajeswaran, MSc, ${ }^{\mathrm{c}}$ \\ Thomas Marwick, MD, PhD, ${ }^{\mathrm{d}}$ Samuel T. Edwards, MD, ${ }^{\mathrm{a}}$ Edward R. Nowicki, MD, MS, ${ }^{\mathrm{b}}$ \\ James Thomas, MD, ${ }^{\mathrm{d}}$ Lars G. Svensson, MD, PhD, FACC, ${ }^{\mathrm{b}}$ Brian Griffin, MD, ${ }^{\mathrm{d}}$ \\ A. Marc Gillinov, MD, FACC, ${ }^{\text {b }}$ and Eugene H. Blackstone, MD, FACC ${ }^{\mathrm{b}, \mathrm{c}}$
}

\begin{abstract}
Objectives: We sought to understand the factors modulating left heart reverse remodeling after aortic valve replacement, the relationship between the preoperative symptoms and modulators of left heart remodeling, and their influence on long-term survival.
\end{abstract}

\begin{abstract}
Methods: From October 1991 to January 2008, 4264 patients underwent primary aortic valve replacement for aortic stenosis. Changes in the time course of left ventricular reverse remodeling were assessed using 5740 postoperative transthoracic echocardiograms from 3841 patients.
\end{abstract}

Results: Left ventricular hypertrophy rapidly declined after surgery, from $137 \pm 42 \mathrm{~g} / \mathrm{m}^{2}$ preoperatively to $115 \pm 27$ by 2 years and remained relatively constant but greater than the upper limit of normal. The most important risk factor for residual left ventricular hypertrophy was greater preoperative left ventricular hypertrophy $(P<.0001)$. Other factors included a greater left atrial diameter (reflecting diastolic dysfunction), a lower ejection fraction, and male gender. An increased postoperative transprosthesis gradient was associated with greater residual left ventricular hypertrophy; however, its effect was minimal. Preoperative severe left ventricular hypertrophy and left atrial dilatation reduced long-term survival, independent of symptom status.

Conclusions: Severe left ventricular hypertrophy with left atrial dilatation can develop from severe aortic stenosis, even without symptoms. These changes can persist, are associated with decreased long-term survival even after successful aortic valve replacement, and could be indications for early aortic valve replacement if supported by findings from an appropriate prospective study. (J Thorac Cardiovasc Surg 2014;147:362-9)

\section{Supplemental material is available online.}

From the Cleveland Clinic Lerner College of Medicine, ${ }^{a}$ Case Western Reserve University, Cleveland, Ohio; and Heart and Vascular Institute, Department of Thoracic and Cardiovascular Surgery, ${ }^{\mathrm{b}}$ Research Institute, Department of Quantitative Health Sciences, ${ }^{c}$ and Heart and Vascular Institute, Department of Cardiovascular Medicine, ${ }^{\mathrm{d}}$ Cleveland Clinic Abu Dhabi, Abu Dhabi, United Arab Emirates.

This work was supported by awards from the American Heart Association (to J.M.B.). It was also supported in part by the Donna and Ken Lewis Chair in Cardiothoracic Surgery (to T.M.); the Charles and Lorraine Moore Endowed Chair in Cardiovascular Imaging (to J.T.); the National Space Biomedical Research Institute through NASA NCC 9-58 (to J.T.); the Judith Dion Pyle Endowed Chair in Heart Valve Research (to A.M.G.); the John and Rosemary Brown Endowed Chair in Cardiovascular Medicine (to B.G.); and the Kenneth Gee and Paula Shaw, PhD, Chair in Heart Research (to E.H.B.)

Disclosures: Dr Gillinov is a consultant for Edwards Lifesciences and receives research support from St Jude Medical and Medtronic. The other authors have nothing to disclose with regard to commercial support.

Received for publication April 10, 2012; revisions received Nov 7, 2012; accepted for publication Dec 5, 2012; available ahead of print Jan 14, 2013.

Address for reprints: Tomislav Mihaljevic, MD, Heart and Vascular Institute, Cleveland Clinic Abu Dhabi, Baniyas Towers, 11th floor, Abu Dhabi, United Arab Emirates (E-mail: mihaljt@ccaduae.ae).

$0022-5223 / \$ 36.00$

Copyright $\odot 2014$ by The American Association for Thoracic Surgery

http://dx.doi.org/10.1016/j.jtcvs.2012.12.016
Long-term survival after aortic valve (AV) replacement (AVR) for aortic stenosis is strongly related to the timing of surgery in the natural disease course. ${ }^{1}$ Left ventricular (LV) hypertrophy and consequent diastolic dysfunction are important consequences of long-standing aortic stenosis that negatively influence postoperative survival. ${ }^{1,2}$ Despite their implications, these measures are largely absent from current symptom-based guidelines for the appropriateness of AVR. ${ }^{3}$

We hypothesized that LV hypertrophy is not fully reversible after AVR and that the factors influencing remodeling and its reversal could be used to refine the guidelines for the optimal timing of AVR in patients with severe aortic stenosis. Therefore, we sought to understand the effect of AVR and other factors that modulate left heart reverse remodeling, the relationship between the preoperative symptoms and the modulators of left heart remodeling, and the influence of the symptoms and left heart remodeling on long-term survival.

\section{METHODS \\ Patients}

From October 1991 to January 2008, 4264 Cleveland Clinic patients underwent primary AVR with a single type of bioprosthesis for severe aortic stenosis, defined as an aortic valve area less than $1 \mathrm{~cm}^{2}$, with or without coronary artery bypass grafting (Table 1 and Table E1). Regurgitation 


$$
\begin{aligned}
& \text { Abbreviations and Acronyms } \\
& \begin{aligned}
\text { AV } & =\text { aortic valve } \\
\text { AVR } & =\text { AV replacement } \\
\text { LA } & =\text { left atrial } \\
\mathrm{LV} & =\text { left ventricular } \\
\mathrm{LVEF} & =\mathrm{LV} \text { ejection fraction } \\
\mathrm{LVMI} & =\mathrm{LV} \text { mass index } \\
\mathrm{TTE} & =\text { transthoracic echocardiogram }
\end{aligned}
\end{aligned}
$$

(mixed lesion) was acceptable if the aortic valve met the criterion for severe aortic stenosis. Patients with predominant aortic regurgitation, infective endocarditis, rheumatic valve disease, or indications for AVR other than aortic stenosis, and those who underwent other concurrent valvar or aortic operations, were excluded.

The preoperative, operative, and postoperative variables were retrieved from the prospective Cleveland Clinic Cardiovascular Information Registry and the echocardiographic variables from the Echocardiography Database. Both have been approved for research by the institutional review board, with patient consent waived.

\section{Echocardiography}

All preoperative measurements were retrieved from the transthoracic echocardiogram (TTE) recorded nearest to, but before, the date of AVR (Table 1). The median interval between the TTE and AVR was 7 days, and $90 \%$ of procedures were performed within 57 days. The LV mass was calculated using the formula validated by Devereux and colleagues. ${ }^{4}$ The peak instantaneous AV gradients were calculated from the Doppler velocity.

Identical measurements were made on all available postoperative TTEs. Echocardiograms were routine before hospital discharge, with follow-up evaluation at the discretion of the referring physician. A total of 8905 postoperative echocardiograms were available for 3850 patients ( $90 \%$ of the population; Figure E1). The LV mass index (LVMI) was available from 5740 TTEs (2696 patients), the left atrial (LA) diameter from 5787 TTEs (2890 patients), the LV ejection fraction (LVEF) from 7506 TTEs (3458 patients), and the AV peak gradient from 7203 TTEs (3492 patients). This permitted reliable evaluation of the temporal trend to 10 years. Patients without postoperative TTEs were included only in the preoperative and survival models.

\section{Follow-up}

Patients were systematically followed up for 2 years and then every 5 years by telephone and mailed questionnaires. These follow-up data were supplemented with Social Security Death Master File data. Followup information was unavailable for 120 patients $(2.8 \%)$. The median follow-up period was 5.7 years (mean, $6.1 \pm 4.0$ years), and 25,878 patient-years of data were available for analysis; $25 \%$ of the living patients were followed up for more than 9 years and $10 \%$ for more than 12 years.

\section{Statistical Analysis}

Left heart reverse remodeling: Time course. Nonlinear mixed-model regression analysis was used to characterize the time course of the postoperative LVMI from the repeated measures data (SAS PROC NLMIXED; SAS Institute, Cary, NC), ${ }^{5}$ using a multiphase parametric model (Appendix E1). This same approach was used to characterize the time courses of the postoperative LA diameter, LVEF, and peak transprosthesis gradient.

Left heart reverse remodeling: Modulators. The preoperative and intraoperative variables (Appendix E2) were screened for an association with the postoperative LVMI, LA diameter, LVEF, and peak transprosthesis gradient using ordinary multivariate linear regression
(SAS PROC REG). The resulting candidates and their transformations were simultaneously entered into each temporal phase and then eliminated individually until all variables remaining had a $P$ value of $\leq .1$. Thereafter, to evaluate the possible effect of the time course of the peak transprosthesis AV gradient on the LVMI, the peak gradient was treated as a timedependent covariable (Appendix E3).

For the investigation of preoperative remodeling, because preoperative variables are importantly related to left heart reverse remodeling, we identified the correlates of preoperative LVMI, LA diameter, and LVEF using linear regression analysis. Variable selection was performed using an automated analysis of 500 bootstrap data sets, with $P \leq .05$ for the retention of variables in the model. ${ }^{6}$ Variables appearing in $50 \%$ or more of the models were considered in the final model.

Left heart remodeling: Symptoms. The associations between the New York Heart Association functional class and preoperative LVMI, LA diameter, and LVEF were determined using Pearson's correlation coefficient. Comparisons of these variables among the New York Heart Association groups were done using the Kruskal-Wallis nonparametric test.

Left heart remodeling: Survival. Survival was assessed nonparametrically using the Kaplan-Meier method and parametrically using a multiphase hazard model that resolved a number of phases of instantaneous risk of death (hazard function). ${ }^{7}$ More information is available at the following web site: my.clevelandclinic.org/professionals/software/haz$\operatorname{ard} /$ default.aspx. "Bagging" was used to identify the preoperative and intraoperative risk factors for death simultaneously for each hazard phase.

To relate the longitudinal LVMI regression to survival, we performed a focused univariate analysis, followed by a multivariate analysis, using the preoperative risk factors (Appendix E2) and postoperative LVMI, with each patient's postoperative LVMI treated as a time-varying function.

\section{Missing Data}

To account for missing values for some covariables, fivefold multiple imputation was performed ${ }^{8}$ for all models using a Markov Chain Monte Carlo technique (SAS PROC MI, version 9.1). Only covariables were imputed, not the outcomes of interest. Bootstrap bagging for variable selection, as described, used 1 imputed data set. Regression coefficients and their variance-covariance matrix for the resulting model were estimated for each imputed data set. These estimates were combined using the method of Rubin to obtain the final estimates reported. ${ }^{8}$

\section{Presentation}

Continuous variables are summarized as the mean \pm standard deviation and as the equivalent 15th, 50th, and 85th percentiles when the values were skewed. Categorical data are summarized as frequencies and percentages. All analyses were performed using SAS statistical software (SAS, version 9.1; SAS Institute). Parametric estimates of postoperative echocardiographic measurements, accompanied by asymmetric $68 \%$ confidence limits, comparable to \pm 1 standard error, were obtained using a bootstrap percentile method. ${ }^{9}$

\section{RESULTS}

\section{Left Heart Reverse Remodeling: Time Course}

LV hypertrophy, as reflected by the LVMI, declined rapidly during the first 3 months after AVR, from $137 \pm 42 \mathrm{~g} / \mathrm{m}^{2}$ preoperatively to $115 \pm 27 \mathrm{~g} / \mathrm{m}^{2}$ by 2 years, and then remained relatively constant, reaching $119 \pm 18 \mathrm{~g} / \mathrm{m}^{2}$ by 10 years (Figure 1). Nevertheless, the LVMI remained greater than the $95 \%$ upper limit of normal (men, $95 \mathrm{~g} / \mathrm{m}^{2}$, women, $75 \mathrm{~g} /$ $\left.\mathrm{m}^{2}\right) .{ }^{10,11}$ In contrast, the LA diameter was unchanged (Figure E2). The LVEF transiently decreased from the preoperative values after AVR but recovered to the preoperative 
TABLE 1. Patient and aortic valve replacement characteristics (total $\mathrm{n}=\mathbf{4 2 6 4 )}$

\begin{tabular}{|c|c|c|}
\hline Characteristic & $\begin{array}{c}\text { Patients with } \\
\text { data available (n) }\end{array}$ & Value \\
\hline \multicolumn{3}{|l|}{ Demographic data } \\
\hline Age (y) & 4264 & $73 \pm 9.2$ \\
\hline Women & 4264 & $1419(33)$ \\
\hline $\operatorname{BSA}\left(\mathrm{m}^{2}\right)$ & 4264 & $2.0 \pm 0.25$ \\
\hline $\begin{array}{l}\text { Symptoms according to NYHA } \\
\text { functional class }\end{array}$ & 4264 & \\
\hline I & & $630(15)$ \\
\hline II & & $2330(55)$ \\
\hline III & & $1007(24)$ \\
\hline IV & & $297(7.0)$ \\
\hline \multicolumn{3}{|l|}{ Aortic valve } \\
\hline Pure aortic stenosis* & 4264 & $2796(66)$ \\
\hline Mixed aortic regurgitation/stenosis $\dagger$ & 4264 & $1468(34)$ \\
\hline Aortic valve stenosis grade & 4264 & \\
\hline Moderate & & $238(5.6)$ \\
\hline Moderately severe & & $360(8.4)$ \\
\hline Severe & & $3666(86)$ \\
\hline Aortic valve regurgitation grade & 4264 & \\
\hline None & & $1521(36)$ \\
\hline Mild & & $1275(30)$ \\
\hline Moderate & & $960(23)$ \\
\hline Moderately severe & & $346(8.1)$ \\
\hline Severe & & $162(3.8)$ \\
\hline Morphology & 4264 & \\
\hline Unicuspid & & $19(0.45)$ \\
\hline Bicuspid & & $1101(26)$ \\
\hline Tricuspid & & $3139(74)$ \\
\hline Quadricuspid & & $5(0.12)$ \\
\hline Orifice area $\left(\mathrm{cm}^{2}\right)$ & 3601 & $0.69 \pm 0.18$ \\
\hline Peak gradient (mm Hg) & 3722 & $77 \pm 27$ \\
\hline Mean gradient (mm Hg) & 3714 & $46 \pm 17$ \\
\hline \multicolumn{3}{|l|}{ Left heart } \\
\hline \multicolumn{3}{|l|}{ Left ventricle } \\
\hline \multicolumn{3}{|l|}{ Structure } \\
\hline Posterior wall thickness $(\mathrm{cm})$ & 3394 & $1.3 \pm 0.23$ \\
\hline $\begin{array}{l}\text { Intraventricular septal wall } \\
\text { thickness }(\mathrm{cm})\end{array}$ & 3438 & $1.5 \pm 0.28$ \\
\hline $\operatorname{LVMI}\left(\mathrm{g} / \mathrm{m}^{2}\right)$ & 3358 & $137 \pm 42$ \\
\hline \multicolumn{3}{|l|}{ Geometry } \\
\hline End-diastolic diameter $(\mathrm{cm})$ & 3483 & $4.8 \pm 0.82$ \\
\hline End-systolic diameter (cm) & 3435 & $3.1 \pm 0.93$ \\
\hline \multicolumn{3}{|l|}{ Function } \\
\hline LV ejection fraction $(\%)$ & 3351 & $52 \pm 13$ \\
\hline \multicolumn{3}{|l|}{ Left atrium } \\
\hline LA diameter $(\mathrm{cm})$ & 3279 & $4.3 \pm 0.75$ \\
\hline \multicolumn{3}{|l|}{ Other cardiac comorbidity } \\
\hline Atrial fibrillation or flutter & 4264 & $240(5.6)$ \\
\hline Complete heart block & 4264 & $194(4.5)$ \\
\hline Ventricular arrhythmia & 4264 & $411(9.6)$ \\
\hline Previous cardiac operations (n) & 4264 & \\
\hline 0 & & $3339(78)$ \\
\hline$\geq 1$ & & $925(22)$ \\
\hline
\end{tabular}

TABLE 1. Continued

\begin{tabular}{|c|c|c|}
\hline Characteristic & $\begin{array}{c}\text { Patients with } \\
\text { data available (n) }\end{array}$ & Value \\
\hline Coronary systems diseased $(\mathrm{n}) \ddagger$ & 4218 & \\
\hline 0 & & $1432(34)$ \\
\hline$\geq 1$ & & $2786(66)$ \\
\hline \multicolumn{3}{|l|}{ Noncardiac comorbidity } \\
\hline $\begin{array}{l}\text { Documented diagnosis } \\
\text { of hypertension }\end{array}$ & 4212 & $3101(74)$ \\
\hline Systolic blood pressure $(\mathrm{mm} \mathrm{Hg})$ & 4251 & $140 \pm 22$ \\
\hline Diastolic blood pressure $(\mathrm{mm} \mathrm{Hg})$ & 4251 & $73 \pm 13$ \\
\hline Smoking & 4222 & $2397(57)$ \\
\hline Peripheral arterial disease & 4264 & $2461(58)$ \\
\hline Carotid disease & 4264 & $2331(55)$ \\
\hline $\begin{array}{l}\text { Chronic obstructive pulmonary } \\
\text { disease }\end{array}$ & 3548 & $886(25)$ \\
\hline Diabetes (treated) & 4179 & $912(22)$ \\
\hline Creatinine $(\mathrm{mg} / \mathrm{dL})$ & 4160 & $1.2 \pm 0.85$ \\
\hline Bilirubin (mg/dL) & 3583 & $0.7 \pm 0.62$ \\
\hline Hematocrit $(\%)$ & 3734 & $39 \pm 5.3$ \\
\hline
\end{tabular}

levels and remained constant (Figure E3). The transvalvar gradient decreased immediately after AVR and remained constant to 10 years, averaging $30 \mathrm{~mm} \mathrm{Hg}$ (Figure 2).

\section{Left Heart Reverse Remodeling: Modulators}

The factors associated with residual LV hypertrophy, in decreasing level of importance, included preoperative LV hypertrophy, LA size, LV systolic dysfunction, and peak transvalvar gradient.

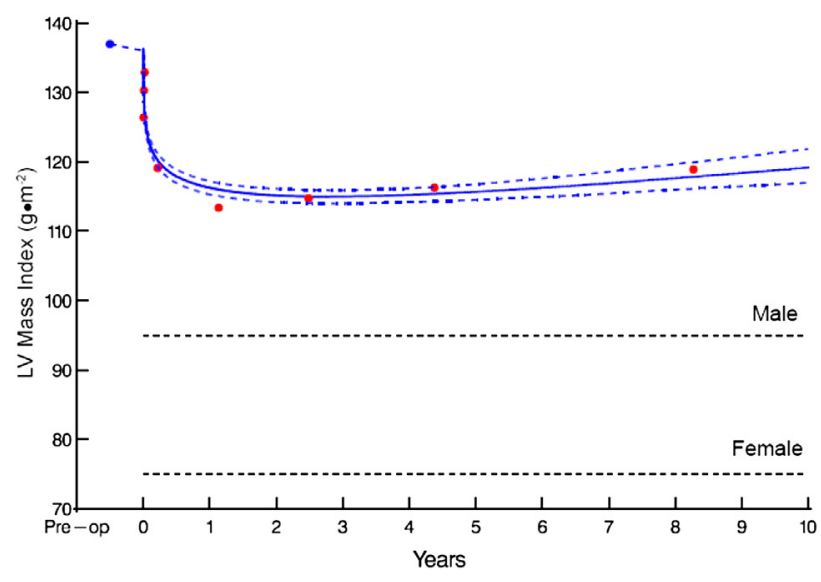

FIGURE 1. Left ventricular $(L V)$ reverse remodeling after aortic valve replacement. Solid line represents unadjusted estimate of temporal trend enclosed within $68 \%$ bootstrap percentile confidence limits. Red circles represent data grouped (without regard to repeated measurements) within time frames to provide crude verification of model fit. Blacked dashed lines depict $95 \%$ upper limit of normal LV mass index for healthy adult men and women. Pre-op, Preoperative. 


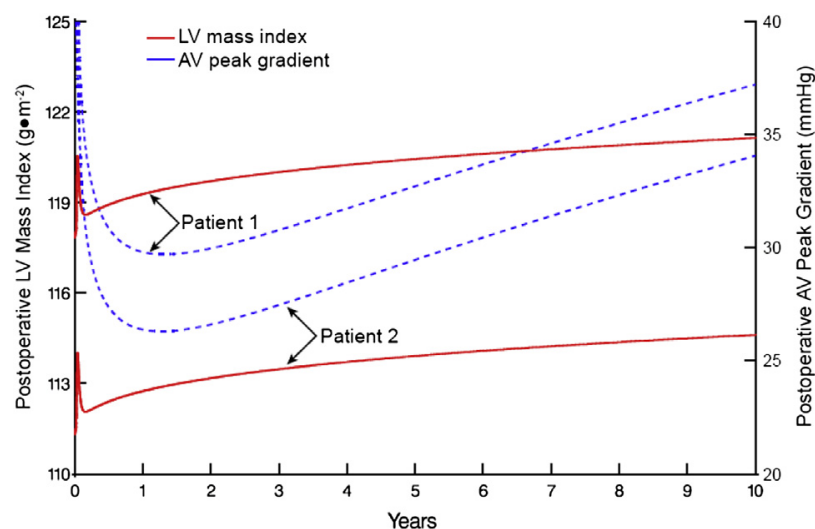

FIGURE 2. Relationship between postoperative aortic valve $(A V)$ peak gradient and postoperative left ventricular $(L V)$ mass index in 2 hypothetical patients. Each patient had a different AV peak gradient profile, with resultant LV mass index in same color, but otherwise identical patient profiles. (This is a nomogram of the multivariate equation in Table 2). Values for preoperative risk factors set as follows: 74-year-old nondiabetic man with no renal disease, no right coronary artery disease (stenosis $>50 \%$ ), 3-cm LV end-systolic diameter, $\mathrm{LV}$ ejection fraction of $55 \%$, left atrial diameter of $4.3 \mathrm{~cm}, \mathrm{AV}$ prosthesis Z-value of -0.45 , and $\mathrm{AV}$ peak gradient of $74 \mathrm{~mm} \mathrm{Hg}$.

The most important factor associated with residual postoperative LV hypertrophy was greater preoperative LV hypertrophy ( $P<.0001$; Table 2 and Figure 3$)$. Patients with greater preoperative LV hypertrophy tended to have more severe aortic stenosis, mixed stenosis and regurgitation, a dilated left atrium (Figure 4), and LV systolic dysfunction (Table E2). Patients with severe LV dysfunction, LA dilatation, and systolic hypertension had more severe residual postoperative LV hypertrophy (Appendix E4).

Severe preoperative LA dilatation was predictive of a larger residual LA size after AVR (Table E3). A larger preoperative LA size was commonly found in older patients with more cardiac and noncardiac comorbidities and associated functional mitral and tricuspid regurgitation (Table E4). Similar preoperative factors were associated with a larger left atrium postoperatively.

Patients with lower LV systolic function preoperatively had a lower LVEF postoperatively (Table E5). Preoperative LV systolic dysfunction was more common in men with more severe aortic stenosis and concomitant coronary artery disease, worse New York Heart Association class, and functional mitral and tricuspid regurgitation (Table E6). Worse postoperative LV systolic function was found in men with cardiac comorbidities and low transprosthesis gradients.

Incomplete LV reverse remodeling was associated with greater postoperative transprosthesis peak gradients. However, even in patients with greater residual gradients, LV reverse remodeling was only modestly impaired (Figure 2). A smaller prosthesis did not impede regression of LV hypertrophy (Table 2). Patients with greater postoperative transprosthesis gradients were more likely to be younger, with smaller prostheses, greater LVMI, and better LV systolic function (Table E7).
TABLE 2. Risk factors associated with greater postoperative LVMI

\begin{tabular}{|c|c|c|}
\hline Factor & Coefficient $\pm \mathrm{SE}$ & $\begin{array}{c}P \\
\text { value }\end{array}$ \\
\hline \multicolumn{3}{|l|}{ Overall } \\
\hline \multicolumn{3}{|l|}{ Preoperative } \\
\hline Larger LVMI* & $0.37 \pm 0.027$ & $<.000$ \\
\hline Women & $0.54 \pm 0.20$ & .006 \\
\hline Interaction (male $\times$ [50/age]) & $0.29 \pm 0.14$ & .04 \\
\hline Interaction $($ female $\times[50 /$ age $])$ & $-0.74 \pm 0.24$ & .002 \\
\hline Larger LV end-systolic diameter $\dagger$ & $0.12 \pm 0.032$ & .01 \\
\hline Larger LA diameter $\ddagger$ & $0.17 \pm 0.076$ & .03 \\
\hline RCA system disease ( $\geq 50 \%$ stenosis) & $0.086 \pm 0.033$ & .009 \\
\hline Greater systolic blood pressure $\S$ & $-0.26 \pm 0.094$ & .007 \\
\hline Diabetes & $0.091 \pm 0.040$ & .02 \\
\hline Renal disease & $0.14 \pm 0.076$ & .06 \\
\hline \multicolumn{3}{|l|}{ Postoperative } \\
\hline Larger postoperative AV peak gradient 9 & $0.23 \pm 0.031$ & $<.000$ \\
\hline \multicolumn{3}{|l|}{ Early phase } \\
\hline Lower LVEF\| & $-0.41 \pm 0.078$ & $<.000$ \\
\hline Larger prosthesis Z-value\# & $0.030 \pm 0.016$ & .06 \\
\hline \multicolumn{3}{|l|}{ Late phase } \\
\hline Lower hematocrit** & $-0.43 \pm 0.24$ & .07 \\
\hline
\end{tabular}

$L V M I$, Left ventricular mass index; $S E$, standard error; $L V$, left ventricular; $L A$, left atrial; $R C A$, right coronary artery; $A V$, aortic valve; $L V E F$, left ventricular ejection fraction. *(LV mass index $/ 125)^{2}$, squared transformation. $\dagger(\mathrm{LV}$ end-systolic diameter $/ 3)^{2}$, squared transformation. $\ddagger(\text { LA diameter } / 5)^{2}$, squared transformation. $\S(135 /$ systolic blood pressure), inverse transformation. $\uparrow \operatorname{Ln}(\mathrm{AV} \text { peak gradient } / 28)^{2}$, squared transformation. $\| \operatorname{Ln}(\mathrm{LV}$ ejection fraction), logarithmic transformation. \#(Exp $[\mathrm{Z} \text {-value/3] })^{2}$, squared transformation. $* *(\text { Hematocrit/40 })^{2}$, squared transformation.

\section{Left Heart Remodeling: Symptoms}

Across a wide range of LVMIs and LA diameters, the symptoms poorly reflected the degree of LV hypertrophy and diastolic dysfunction (Figure E5), with the distribution of values broadly overlapping. When the LVMI was $180 \mathrm{~g} / \mathrm{m}^{2}$ or greater, $14 \%$ of patients were asymptomatic and $50 \%$

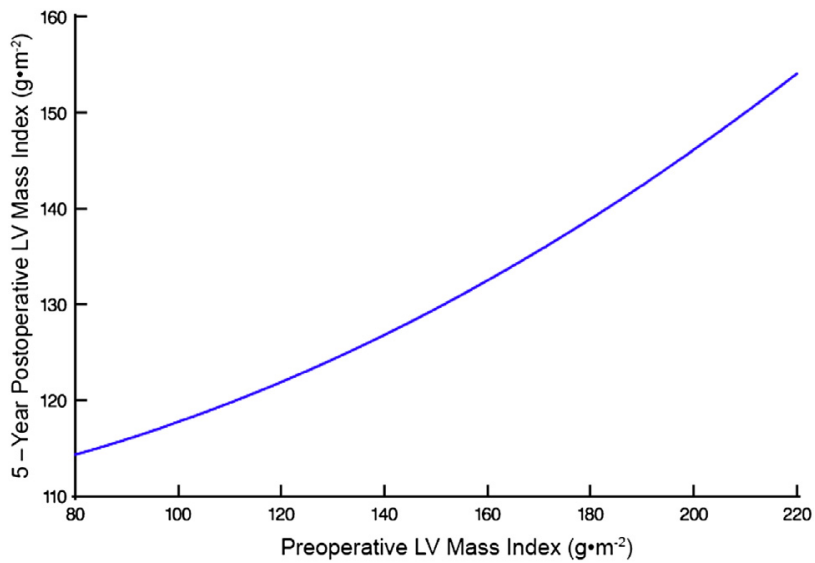

FIGURE 3. Relationship of residual left ventricular $(L V)$ hypertrophy to degree of preoperative hypertrophy. (This is a nomogram of multivariate equation in Table 2, solved for 5-year predicted postoperative vs preoperative LV mass index). Values for preoperative risk factors set as in Figure 2, except for LV mass index of $130 \mathrm{~g} / \mathrm{m}^{2}$. 


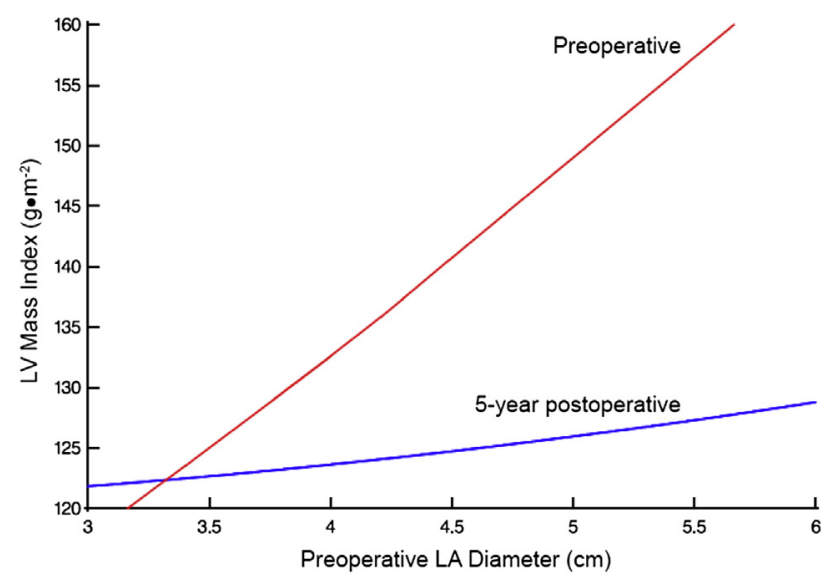

FIGURE 4. Relationship between preoperative left atrial $(L A)$ diameter and both preoperative and 5-year postoperative left ventricular $(L V)$ hypertrophy. Blue line depicts relationship between preoperative LA diameter and 5-year postoperative LV mass index. (This is a nomogram of the multivariate equation in Table 2, as described in Figure 2). Red line depicts relationship between preoperative LV mass index and preoperative LA diameter, obtained using nonparametric local regression method.

mildly symptomatic. When the LA diameter was $5 \mathrm{~cm}$ or greater, $12 \%$ of patients were asymptomatic and $47 \%$ mildly symptomatic.

\section{Left Heart Remodeling: Survival}

The patients with severe LV hypertrophy $\left(\geq 180 \mathrm{~g} / \mathrm{m}^{2}\right)$ had reduced long-term survival compared with the patients with a LVMI of less than $96 \mathrm{~g} / \mathrm{m}^{2}$ at 5 years $(73 \%$ vs $81 \%)$ and 10 years $(45 \%$ vs $56 \%)$, despite successful AVR $(P=.08$; Figure $5, A)$. Patients with a severely enlarged left atrium $(\geq 5.0-\mathrm{cm}$ diameter) had substantially reduced long-term survival compared to patients with a diameter of less than $3.55 \mathrm{~cm}$ at $5(61 \%$ vs $85 \%)$ and $10(28 \%$ vs $62 \%)$ years after AVR $(P=.006$; Figure $5, B)$. The steep continuous association of the LA diameter with survival is demonstrated in Figure 6; only $51 \%$ of patients with a diameter of $4 \mathrm{~cm}$ were alive 10 years after AVR.

Although greater residual LV hypertrophy was related to a greater risk of late mortality after AVR (Figure E7 and Table E8), on multivariate analysis, a greater degree of preoperative LV hypertrophy was the more statistically significant risk factor (Table E9).

\section{DISCUSSION \\ Principal Findings}

AVR in patients with severe aortic stenosis results in rapid, but incomplete, LV reverse remodeling. Greater residual LV hypertrophy was present in patients with more severe preoperative LV hypertrophy, a larger LA diameter, and worse LV function. A greater postoperative transprosthesis gradient had a minimal association with residual LV hypertrophy. The preoperative symptoms were
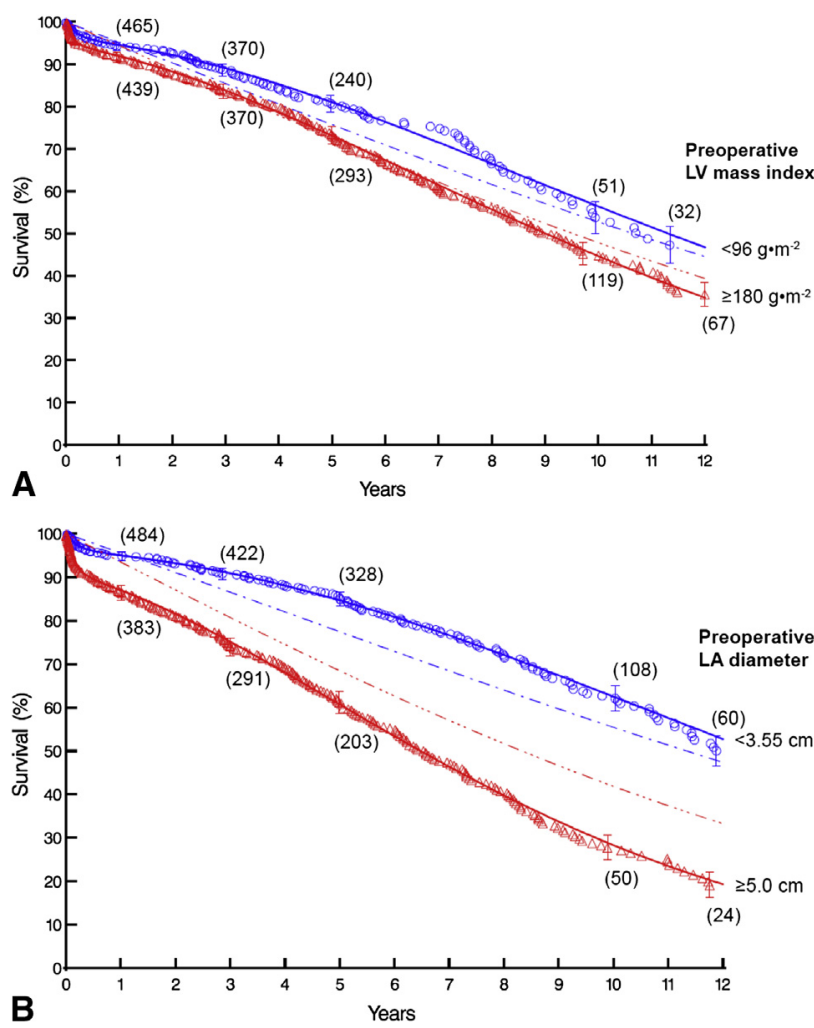

FIGURE 5. Stratified survival after aortic valve replacement. Each symbol represents a death, vertical bars represent $68 \%$ confidence limits, equivalent to \pm 1 standard error, and numbers in parentheses represent patients remaining at risk. Solid lines are parametric estimates, and dashed lines in corresponding color represent survival of an age-race-gender-matched population. A, Severity of left ventricular $(L V)$ hypertrophy. For clarity, only patients with extreme values depicted (LV mass index, $<96 \mathrm{~g} / \mathrm{m}^{2}$ in 15th percentile and $\geq 180 \mathrm{~g} / \mathrm{m}^{2}$ in 85 th percentile). B, Left atrial $(L A)$ diameter $(<3.55 \mathrm{~cm}$ in 15 th percentile and $\geq 5.0 \mathrm{~cm}$ in 85 th percentile).

not suggestive of the degree of LV hypertrophy or diastolic dysfunction; however, both, in particular, the latter, were associated with decreased long-term survival.

\section{Reverse Remodeling: Time Course}

Although LV hypertrophy declined rapidly after AVR, on average, it remained greater than the upper limit of normal, consistent with findings from others. ${ }^{12,13}$ This suggests that even successful AVR, in accordance with current guidelines, does not result in full recovery of the left ventricle.

\section{Reverse Remodeling: Modulators}

The evaluation of patients with aortic stenosis must account, not only for changes in valve size and function, but also the effects of chronicity and severity on the heart. LV hypertrophy is often considered a benign adaptive response. However, we, and others, have demonstrated that the more severe the LV hypertrophy at surgery, the greater the amount of residual LV hypertrophy after 


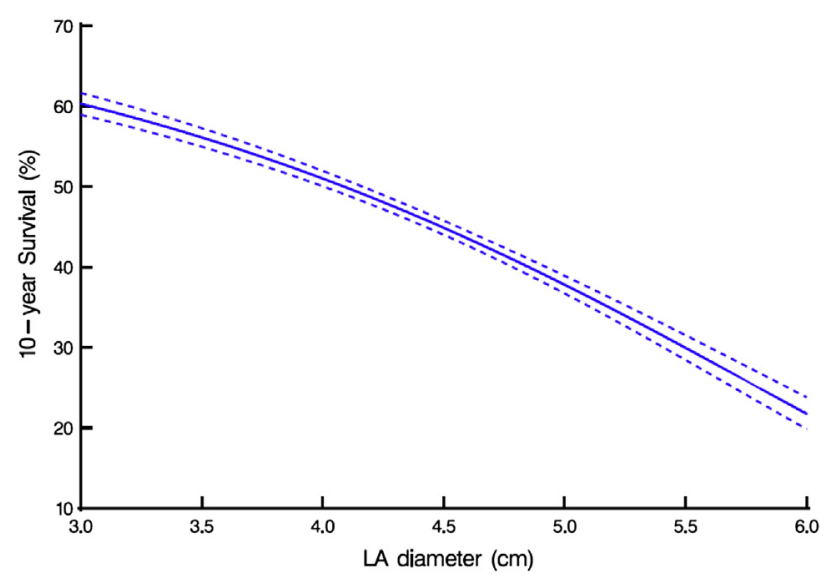

FIGURE 6. Non-risk-adjusted relationships of left atrial $(L A)$ diameter to 10-year survival after aortic valve replacement. Parametric estimate enclosed within $68 \%$ confidence band.

AVR. ${ }^{12,13}$ The factors associated with greater preoperative LV hypertrophy, such as a smaller AV orifice area and severely calcified leaflets, result in increased gradients and associated regurgitation. Therefore, defining aortic stenosis severity should include factors other than the AV orifice area, jet velocity, and mean gradient. ${ }^{3}$

LV hypertrophy from long-standing aortic stenosis results in decreased ventricular compliance and ischemiainduced myocardial fibrosis, ${ }^{14,15}$ contributing to LV diastolic dysfunction. ${ }^{16}$ We observed that preoperative LA dilatation, reflecting the chronicity and diastolic dysfunction severity, ${ }^{17}$ is associated with greater LV hypertrophy before and after surgery. In the present study, the LA diameter did not decrease after AVR, even after LV reverse remodeling was completed. Previous studies have shown that diastolic dysfunction can even worsen in the long term after AVR, ${ }^{2}$ suggesting that diastolic dysfunction is yet another enduring consequence of aortic stenosis, even after successful AVR.

More severe aortic stenosis was associated with decreased LVEF and, after AVR, less complete LV reverse remodeling. Although the focus is frequently on systolic dysfunction, it is important to emphasize that a decrease in LVEF is a late sign of disease progression, often a consequence of ischemia, fibrosis, and coronary artery disease. ${ }^{18,19}$

Incomplete LV reverse remodeling has been linked to the transprosthesis gradient after AVR, causing prosthesis-patient mismatch. ${ }^{20} \mathrm{We}$ found only a modest effect of an elevated postoperative transprosthesis gradient on residual LV hypertrophy, a unique contribution of the present study. The presence of preoperative LV hypertrophy and the LA diameter are much stronger predictors of postoperative LV recovery.

Preoperative LV hypertrophy can reflect other disease processes, such as hypertension, that contribute to chronic afterload elevation. Angiotensin-converting enzyme inhibitors have been shown to be safe in the context of mild and moderate aortic stenosis. ${ }^{21}$ In the context of severe aortic stenosis, the Symptomatic Cardiac Obstruction-Pilot Study of Enalapril in Aortic Stenosis (SCOPE-AS) randomized trial has demonstrated that angiotensin-converting enzyme inhibitors improve symptoms and exercise tolerance. However, in patients with heart failure and LV dysfunction without hypertension, an angiotensin-converting enzyme inhibitor should not be used because hypotension can ensue. $^{22}$

\section{Left Heart Remodeling: Symptoms}

The current indications for surgery in patients with severe aortic stenosis are heavily symptom based. ${ }^{3}$ However, their presence can be difficult to ascertain and their absence misleading. ${ }^{23,24}$ The use of exercise stress testing or the 6-minute walk test can augment the evaluation of these patients. One third to two thirds of patients who report no symptoms develop exercise-induced symptoms, ${ }^{25}$ and these patients are more likely to develop spontaneous symptoms earlier than those with negative test findings.

Consistent with others, we found that the degree of LV hypertrophy and diastolic dysfunction were risk factors for mortality after AVR but correlated poorly with the symptom severity. ${ }^{26}$ Symptom status was neither reflective of the state of the myocardium nor the disease severity and should not be the primary indication for surgical intervention.

\section{Left Heart Remodeling: Survival}

The importance of LV hypertrophy and LA size was further underscored through their association with survival. The known risk factors for mortality after AVR for aortic stenosis include older age, greater functional class, severe symptoms, and LV hypertrophy. ${ }^{1}$ We add the important risk factor of LV diastolic dysfunction, as reflected by an increased LA diameter. Compared with Mihaljevic and colleagues, ${ }^{1}$ our data have shown a relatively diminished effect of LV hypertrophy on survival after updating the original cohort, with more patients and longer follow-up and including the LA diameter in the analysis. However, we noted an impressive $34 \%$ decrease in 10-year survival in patients with dilated left atria. Similar to LV hypertrophy, diastolic dysfunction is not benign and has been identified as a predictor of mortality before the development of symptoms ${ }^{27}$ and late mortality after AVR in patients with aortic stenosis. ${ }^{2}$ The LA diameter is powerfully associated with long-term survival and underscores the importance of assessing LV diastolic dysfunction in preoperative decision making.

\section{Strengths and Limitations}

In the present single-institution observational study, we had opportunistic, rather than systematic, echocardiographic follow-up data available. We could not know whether patients had follow-up TTEs available randomly 
or informatively. Because our institution is a referral center, many patients are followed up entirely by their local cardiologist. To address this, a subset of more than 1000 patients with echocardiographic follow-up at the Cleveland Clinic for longer than 6 months was analyzed, and the findings were consistent with those of the overall groups (Appendix E5). Despite these limitations, the number of available postoperative echocardiograms was larger than that of other known studies, and powerful longitudinal data analysis techniques enabled incorporating multiple measurements over time at disparate intervals instead of using designated measurement points. ${ }^{12}$ To our knowledge, only 1 study has used these techniques to examine the changes in LV hypertrophy after $\mathrm{AVR}^{13}$; however, in contrast, we studied more patients and variables.

Another limitation not unique to our study was that our primary predictor, LV hypertrophy, can be influenced by common diseases not deeply investigated in the present study, notably, systemic hypertension. Preoperative hypertension was associated with increased preoperative LV hypertrophy and incomplete LV reverse remodeling; however, we did not have longitudinal postoperative blood pressure data available to determine its time-varying influence on $\mathrm{LV}$ reverse remodeling. We were also limited by the accuracy and variability of our echocardiographic measurements over time and between observers. However, this would blunt an effect rather than introduce a spurious one. Additionally, we were restricted to the LA diameter as a surrogate for diastolic dysfunction. However, the LA diameter is nearly linearly correlated with the LVMI and, as others have demonstrated, prognostically powerful. ${ }^{2,28}$ The indexed LA diameter was not as strong a risk factor as the unindexed size.

However, many factors occurring after AVR also affect survival, such as atrial and ventricular arrhythmia, progressive degeneration of the prosthesis, stroke, and other adverse valve-related and nonvalve-related outcomes. We did not consider any of the postoperative events as time-varying covariables in our modeling. Because the occurrence and timing of other events are not known preoperatively, their inclusion in analyses such as we have performed is arguable.

\section{CONCLUSIONS}

LV hypertrophy and, more notably, diastolic dysfunction are consequences of long-standing aortic stenosis and are powerful predictors of long-term survival after AVR. The LV mass and LA diameter are easily and routinely measured and monitored echocardiographically, in contrast to symptoms, which can be unreliable and difficult to elicit, ${ }^{24,29}$ yet still represent the primary indication for treatment. ${ }^{3} \mathrm{We}$ have shown that patients can have advanced changes in the absence of symptoms, underscoring the inadequacy of symptom presence as the sole guideline for the timing of AVR.
This indicates that the condition of the heart at surgery powerfully influences patient outcomes. Our study adds to the volume of data suggesting that symptoms alone should not be used to determine the optimal timing of treatment in patients with aortic stenosis. The clinical challenge in asymptomatic patients with severe aortic stenosis is to detect deleterious left heart remodeling at the subclinical stage to perform AVR before the occurrence of irreversible changes that diminish the long-term benefit of surgery. Our data suggest that an LA diameter greater than $4 \mathrm{~cm}$ in the context of severe LV hypertrophy could be an indication for early AVR in patients with severe aortic stenosis, even in the absence of symptoms, if supported by an appropriate prospective study.

\section{References}

1. Mihaljevic T, Nowicki ER, Rajeswaran J, Blackstone EH, Lagazzi L, Thomas J, et al. Survival after valve replacement for aortic stenosis: implications for decision making. J Thorac Cardiovasc Surg. 2008;135:1270-9.

2. Gjertsson P, Caidahl K, Bech-Hanssen O. Left ventricular diastolic dysfunction late after aortic valve replacement in patients with aortic stenosis. Am J Cardiol. 2005; $96: 722-7$

3. Bonow RO, Carabello BA, Chatterjee K, de Leon AC Jr, Faxon DP, Freed MD, et al. 2008 Focused update incorporated into the ACC/AHA 2006 guidelines for the management of patients with valvular heart disease: a report of the American College of Cardiology/American Heart Association Task Force on Practice Guidelines (Writing Committee to revise the 1998 guidelines for the management of patients with valvular heart disease). Endorsed by the Society of Cardiovascular Anesthesiologists, Society for Cardiovascular Angiography and Interventions, and Society of Thoracic Surgeons. J Am Coll Cardiol. 2008;52:e1-142.

4. Devereux RB, Alonso DR, Lutas EM, Gottlieb GJ, Campo E, Sachs I, et al. Echocardiographic assessment of left ventricular hypertrophy: comparison to necropsy findings. Am J Cardiol. 1986;57:450-8.

5. Diggle PJ, Heagerty PJ, Liang KY, Zeger SL. Analysis of longitudinal data. 2nd ed. New York: Oxford University Press; 2002.

6. Breiman L. Bagging predictors. Machine Learning. 1996;24:123-40.

7. Blackstone EH, Naftel DC, Turner ME Jr. The decomposition of time-varying hazard into phases, each incorporating a separate stream of concomitant information. J Am Stat Assoc. 1986;81:615-24.

8. Rubin DB. Multiple imputation for non-response in surveys. New York: Wiley; 1987.

9. Efron B, Tibshirani RJ. An introduction to the bootstrap. New York: Chapman and Hall/CRC; 1998.

10. Salton CJ, Chuang ML, O’Donnell CJ, Kupka MJ, Larson MG, Kissinger KV, et al. Gender differences and normal left ventricular anatomy in an adult population free of hypertension: a cardiovascular magnetic resonance study of the Framingham Heart Study Offspring cohort. J Am Coll Cardiol. 2002;39:1055-60.

11. Lin FY, Devereux RB, Roman MJ, Meng J, Jow VM, Jacobs A, et al. Cardiac chamber volumes, function, and mass as determined by 64-multidetector row computed tomography: mean values among healthy adults free of hypertension and obesity. JACC Cardiovasc Imaging. 2008;1:782-6.

12. Lund O, Erlandsen M, Dorup I, Emmertsen K, Flo C, Jensen FT. Predictable changes in left ventricular mass and function during ten years after valve replacement for aortic stenosis. J Heart Valve Dis. 2004;13:357-68.

13. Lim E, Ali A, Theodorou P, Sousa I, Ashrafian H, Chamageorgakis T, et al. Longitudinal study of the profile and predictors of left ventricular mass regression after stentless aortic valve replacement. Ann Thorac Surg. 2008;85:2026-9.

14. Azevedo CF, Nigri M, Higuchi ML, Pomerantzeff PM, Spina GS, Sampaio RO, et al. Prognostic significance of myocardial fibrosis quantification by histopathology and magnetic resonance imaging in patients with severe aortic valve disease. J Am Coll Cardiol. 2010;56:278-87.

15. Weidemann F, Herrmann S, Stork S, Niemann M, Frantz S, Lange V, et al. Impact of myocardial fibrosis in patients with symptomatic severe aortic stenosis. Circulation. 2009;120:577-84

16. Dalsgaard M, Egstrup K, Wachtell K, Gerdts E, Cramariuc D, Kjaergaard J, et al. Left atrial volume in patients with asymptomatic aortic valve stenosis (the Simvastatin and Ezetimibe in Aortic Stenosis study). Am J Cardiol. 2008;101: $1030-4$. 
17. De Castro S, Caselli S, Di Angelantonio E, Del Colle S, Mirabelli F, Marcantonio A, et al. Relation of left atrial maximal volume measured by realtime 3D echocardiography to demographic, clinical, and Doppler variables. Am J Cardiol. 2008;101:1347-52.

18. Tarantini G, Buja P, Scognamiglio R, Razzolini R, Gerosa G, Isabella G, et al. Aortic valve replacement in severe aortic stenosis with left ventricular dysfunction: determinants of cardiac mortality and ventricular function recovery. Eur J Cardiothorac Surg. 2003;24:879-85.

19. Lamb HJ, Beyerbacht HP, de Roos A, van der Laarse A, Vliegen HW, Leujes F, et al. Left ventricular remodeling early after aortic valve replacement: differential effects on diastolic function in aortic valve stenosis and aortic regurgitation. J Am Coll Cardiol. 2002;40:2182-8.

20. Kulik A, Burwash IG, Kapila V, Mesana TG, Ruel M. Long-term outcomes after valve replacement for low-gradient aortic stenosis: impact of prosthesis-patient mismatch. Circulation. 2006;114:I553-8.

21. O'Brien KD, Zhao XQ, Shavelle DM, Caulfield MT, Letterer RA, Kapadia SR, et al. Hemodynamic effects of the angiotensin-converting enzyme inhibitor, ramipril, in patients with mild to moderate aortic stenosis and preserved left ventricular function. J Invest Med. 2004;52:185-91.

22. Chockalingam A, Venkatesan S, Subramaniam T, Jagannathan V, Elangovan S, Alagesan R, et al. Safety and efficacy of angiotensin-converting enzyme inhibitors in symptomatic severe aortic stenosis: Symptomatic Cardiac
Obstruction-Pilot Study of Enalapril in Aortic Stenosis (SCOPE-AS). Am Heart J. 2004;147:E19.

23. Amato MC, Moffa PJ, Werner KE, Ramires JA. Treatment decision in asymptomatic aortic valve stenosis: role of exercise testing. Heart. 2001; 86:381-6.

24. Otto CM. Valvular aortic stenosis: disease severity and timing of intervention. J Am Coll Cardiol. 2006;47:2141-51.

25. Das P, Rimington H, Chambers J. Exercise testing to stratify risk in aortic stenosis. Eur Heart J. 2005;26:1309-13.

26. Stewart RA, Kerr AJ, Whalley GA, Legget ME, Zeng I, Williams MJ, et al. New Zealand Heart Valve Study Investigators. Left ventricular systolic and diastolic function assessed by tissue Doppler imaging and outcome in asymptomatic aortic stenosis. Eur Heart J. 2010;31:2191-3.

27. Casaclang-Verzosa G, Malouf JF, Scott CG, Juracan EM, Nishimura RA Pellikka PA. Does left atrial size predict mortality in asymptomatic patients with severe aortic stenosis? Echocardiography. 2010;27:105-9.

28. Gjertsson P, Caidahl K, Farasati M, Oden A, Bech-Hanssen O. Preoperative moderate to severe diastolic dysfunction: a novel Doppler echocardiographic long-term prognostic factor in patients with severe aortic stenosis. $J$ Thorac Cardiovasc Surg. 2005;129:890-6.

29. Stout KK, Otto CM. Indications for aortic valve replacement in aortic stenosis. J Intensive Care Med. 2007;22:14-25. 


\section{APPENDIX E1. NONLINEAR MIXED-MODEL REGRESSION AND SHAPING PARAMETERS FOR TEMPORAL TRENDS}

In brief, this method accounts for the possibility of a varying influence of factors on the temporal rate of left ventricular (LV) reverse remodeling during periods of early rapid change versus late slow change (similar to nonproportional hazards in a survival analysis). It does so by identifying additive time phases, each having different shaping parameters. ${ }^{\mathrm{E} 3}$ Each data-driven phase has a sealing parameter that is a function of risk factors. Because of the method's mathematical properties (orthogonality), the same set of factors can be considered simultaneously in each temporal phase.

\section{Temporal Trend of LV Mass Index}

The LV mass index at time $t$ was modeled as the following mixed model:

$$
\left(\frac{\text { LV Mass Index }(\mathrm{t})-120}{40}\right)=\log (E(t)+L(t))+u,
$$

where $E(t)=\frac{0.61}{\exp \left\{(0.008 t)^{0.9}\right\}(0.008 t)^{0.09}}, L(t)=0.0296 t$, and $u$ is the patient-specific random effect (intercept). We assumed a normal distribution for the random effects and error.

\section{Temporal Trend of LV Ejection Fraction}

The LV ejection fraction at time $t$ was modeled as the following mixed model:

$$
\left(\frac{\operatorname{LVEF}(t)-50}{12}\right)=\log (E(t)+C)+u,
$$

where $E(t)=\frac{0.004}{\exp \left\{(0.0001 t)^{-0.2}\right\}(0.0001 t)^{1.2}}, C=1.8859$, and $u$ is the patient-specific random effect (intercept) with distributional assumption as above.

\section{Temporal Trend of Left Atrial Diameter}

The left atrial (LA) diameter at time $t$ was modeled as the following mixed model:

$$
\left(\frac{\text { LA Diameter }(t)}{4.5}\right)=\log (E(t)+C+L(t))+u,
$$

where $\quad E(t)=\frac{0.12}{\exp \left\{(4.87 t)^{-0.61}\right\}(4.87 t)^{1.61}}, \quad C=2.61$, $L(t)=0.018 t$, and $u$ is the patient-specific random effect (intercept) with distributional assumption as above.

\section{Temporal Trend of Aortic Valve Peak Gradient}

Aortic valve (AV) peak gradient at time $t$ was modeled as the following mixed model:

$$
\left(\frac{\text { AV Peak Gradient }(t)}{25}\right)=\log (E(t)+C+L(t))+u,
$$

where

$$
E(t)=\frac{0.98}{\exp \left\{(21.7 t)^{-2.4}\right\}(21.7 t)^{3.4}}, \quad C=2.8,
$$

$L(t)=0.40(0.3 t)^{0.35}$, and $u$ is the patient-specific random effect (intercept) with distributional assumption as above.

\section{APPENDIX E2. VARIABLES USED IN ANALYSES Patient Data}

Demographic data: Age (y), gender, weight $(\mathrm{kg})$, height $(\mathrm{cm})$, body surface area $\left(\mathrm{m}^{2}\right)$, body mass index $\left(\mathrm{kg} / \mathrm{m}^{2}\right)$

Symptoms: New York Heart Association functional class (I-IV), emergency surgery

Aortic valve

Physiology: Aortic valve regurgitation, aortic valve stenosis, orifice area $\left(\mathrm{cm}^{2}\right)$, mean gradient $(\mathrm{mm}$ $\mathrm{Hg}$ ), peak gradient $(\mathrm{mm} \mathrm{Hg})$

Etiology: Degenerative

Morphology: Calcification, thickened leaflets, fused commissures, perforation, bicuspid valve

Other valvar pathology: Tricuspid valve regurgitation, mitral valve regurgitation

Coronary anatomy: Left main trunk disease (percentage of stenosis), left anterior descending coronary artery system disease (maximum \% stenosis), right coronary artery system disease (maximum \% stenosis), left circumflex coronary artery system disease (maximum percentage of stenosis)

Ventricular dysfunction: Previous myocardial infarction, degree of left ventricular dysfunction (1, none; 2 , mild; 3 , moderate; 4 , severe)

Left ventricle

Structure: Inner diameter in diastole $(\mathrm{cm})$, inner diameter in systole $(\mathrm{cm})$, diastolic volume $(\mathrm{mL})$, systolic volume $(\mathrm{mL})$, diastolic volume index $\left(\mathrm{mL} / \mathrm{m}^{2}\right)$, systolic volume index $\left(\mathrm{mL} / \mathrm{m}^{2}\right)$, dilated left ventricle

Function: Fractional shortening, ejection fraction (\%), relative wall thickness (wall stress), LV dysfunction (grade: none, mild, mild to moderate, moderate, moderate to severe, severe)

Mass: Mass (g), mass index $\left(\mathrm{g} / \mathrm{m}^{2}\right)$, posterior wall thickness $(\mathrm{cm})$, septal thickness $(\mathrm{cm})$

Left atrium: Left atrial diameter $(\mathrm{cm})$, volume $\left(\mathrm{cm}^{3}\right)$, volume index $(\mathrm{mL} / \mathrm{m})$ 
Other cardiovascular comorbidity: Preoperative atrial fibrillation, documented diagnosis of hypertension, complete heart block requiring pacemaker, ventricular arrhythmia, ascending aortic aneurysm, peripheral arterial disease, smoking, carotid disease, systolic and diastolic blood pressure $(\mathrm{mm} \mathrm{Hg})$

Noncardiac comorbidity: Treated diabetes, insulintreated diabetes, creatinine $(\mathrm{mg} / \mathrm{dL})$, blood urea nitrogen $(\mathrm{mg} / \mathrm{dL})$, bilirubin $(\mathrm{mg} / \mathrm{dL})$, creatinine clearance, hematocrit $(\%)$

\section{Intraoperative}

Aortic valve prosthesis: Valve size $(\mathrm{mm})$, in vitro effective orifice area $\left(\mathrm{cm}^{2}\right), \mathrm{Z}$-value, Z-value for effective orifice area, valve area/body surface area ratio $\left(\mathrm{cm}^{2} / \mathrm{m}^{2}\right)$, effective orifice area/body surface area
In the longitudinal data analysis, a time-varying covariate can be considered as a covariate in a longitudinal model if the covariate process satisfies the assumption of exogeneity. A covariate process is exogenous with respect to an outcome process if the covariate at time $t$ is conditionally independent of all preceding response measurements.

Thus, suppose $X_{i t}$ is the covariate value for patient $i$ at time $t, H_{i}^{X}(t-1)$ is the history of the covariate process up to time $t-1, H_{i}^{Y}(t)$ is the response process up to time $t$, and $Z_{i}$ is the baseline covariate, then the covariate process is exogenous if, and only if,

$$
f\left(X_{i t} \mid H_{i}^{Y}(t), H_{i}^{X}(t-1), Z_{i}\right)=f\left(X_{i t} \mid H_{i}^{X}(t-1), Z_{i}\right) .
$$

Now, under this exogeneity assumption, we can include the time-varying covariate postoperative gradient at time $t$ in the longitudinal model described in Appendix E1 as follows:

$$
\left(\frac{\mathrm{LV} \text { Mass Index }(\mathrm{t})-120}{40}\right)=\left\{\mathrm{Z}_{1} \beta_{1}+\theta \log (\text { post }- \text { op peak gradient }(\mathrm{t}))\right\}+\log \left(\exp \left(\mathrm{Z}_{2} \beta_{2}\right) E(t)+\exp \left(\mathrm{Z}_{3} \beta_{3}\right) L(t)\right)+u
$$

ratio $\left(\mathrm{cm}^{2} / \mathrm{m}^{2}\right)$, internal valve area $\left(\mathrm{cm}^{2}\right)$, effective orifice area/internal area efficiency

Other procedure: Internal thoracic artery graft used, coronary artery bypass grafting

Support: Aortic clamp time (min), cardiopulmonary bypass time (min)

Experience: Date of operation (years since January 1, 1991)

\section{APPENDIX E3. BRIEF DESCRIPTION OF METHODOLOGY TREATING AORTIC VALVE GRADIENT AS A TIME-DEPENDENT COVARIABLE}

The outcome of interest was the temporal pattern of postoperative left ventricular (LV) mass index after aortic valve (AV) replacement, and we assessed the effect of the postoperative AV peak gradient on this temporal pattern. Thus, we treated the postoperative AV peak gradient as a covariate and assessed its influence on the longitudinal response, postoperative LV mass index. However, the covariate, AV peak gradient, unlike the baseline variables (eg, gender) that were observed at AVR, changed with time. Thus, we assessed the influence of a covariate that changed with time and was observed after we started observing the longitudinal response. Therefore, in this scenario, we treated the postoperative $\mathrm{AV}$ peak gradient as a time-varying covariate. where Log is the natural logarithm and exp is the exponential function.

\section{APPENDIX E4. INFLUENCE OF DEMOGRAPHICS ON LEFT VENTRICULAR REVERSE REMODELING}

Severe postoperative left ventricular (LV) hypertrophy was more common in men and was not age dependent. It was considerably less pronounced in younger women, but increased with age (Figure E4, $A$ ). This relationship among age, gender, and residual LV hypertrophy also existed preoperatively (Figure E4, B).

Younger patients with smaller left atria at surgery had better survival than those with a larger diameter (Figure E6). More symptomatic patients (New York Heart Association functional class III or IV) experienced both greater early mortality (30-day mortality, 50/2960 [1.7\%] vs 45/1304 [3.4\%] for patients in New York Heart Association I-II vs III-IV) and late mortality.

We observed significant gender differences in LV reverse remodeling. More severe postoperative LV hypertrophy was evident in elderly women. This finding was likely because women have a smaller aortic valve (AV) orifice area, leading to an increased transvalvar gradient. These findings are most notable in elderly women with ventricles 
that have been exposed to these conditions for longer. Such women have been noted to have greater LV peak systolic pressures and systolic function, possibly contributing to the development of more LV hypertrophy compared with men over time. ${ }^{\mathrm{E} 4, \mathrm{E} 5}$

The left atrial diameter is powerfully associated with long-term survival, especially in younger patients, and underscores the importance of assessing LV diastolic dysfunction in preoperative decision making.

\section{APPENDIX E5. ANALYSIS OF ECHOCARDIOGRAMS OF PATIENTS FOLLOWED UP AT CLEVELAND CLINIC FOR MORE THAN 6 MONTHS}

The number of available transthoracic echocardiograms (TTEs) during follow-up decreased dramatically at the same time as the greatest changes occurred in left heart remodeling (Figure 1 and Figures E1-E3). To address the possibility that this was an artifact of TTE availability, rather than a biologic phenomenon, we analyzed the TTEs of patients with studies after 6 months or more of follow-up at Cleveland Clinic, including all preoperative studies for these patients before 6 months. Modes of

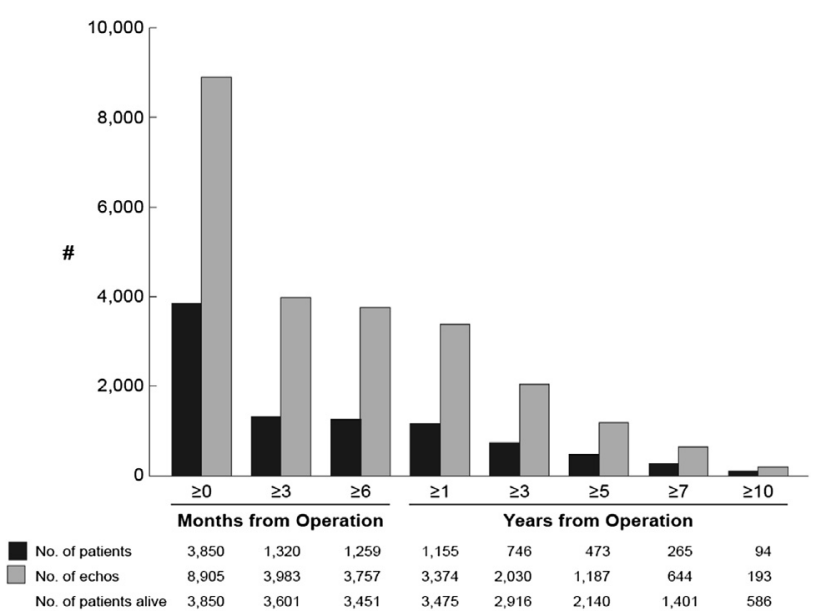

FIGURE E1. Number of patients with postoperative echocardiograms available at and beyond various measurement points, number of echocardiograms available for analysis, and number of patients alive at each point. increased frequency of TTEs were present at yearly intervals, most notably during the first 5 years (Figure E8). This suggests substantial data from routinely scheduled visits were available for analysis. The results of echocardiographic analyses (Figure E9) mirror those presented in Figure 1 and Figures E2 and E3.

\section{E-References}

E1. Blackstone EH, Cosgrove DM, Jamieson WR, Birkmeyer NJ, Lemmer JH Jr, Miller DC, et al. Prosthesis size and long-term survival after aortic valve replacement. J Thorac Cardiovasc Surg. 2003;126:783-96.

E2. Lang RM, Bierig M, Devereux RB, Flachskampf FA, Foster E, Pelikka PA, et al. American Society of Echocardiography's Nomenclature and Standards Committee; Task Force on Chamber Quantification; American College of Cardiology Echocardiography Committee; American Heart Association; European Association of Echocardiography, European Society of Cardiology. Recommendations for chamber quantification. Eur J Echocardiogr. 2006;7:79-108.

E3. Blackstone EH, Naftel DC, Turner ME Jr. The decomposition of time-varying hazard into phases, each incorporating a separate stream of concomitant information. J Am Stat Assoc. 1986;81:615-24.

E4. Favero L, Giordan M, Tarantini G, Ramondo AB, Cardaioli P, Isabella G, et al. Gender differences in left ventricular function in patients with isolated aortic stenosis. J Heart Valve Dis. 2003;12:313-8.

E5. Rohde LE, Zhi G, Aranki SF, Beckel NE, Lee RT, Reimold SC. Gender associated differences in left ventricular geometry in patients with aortic valve disease and effect of distinct overload subsets. Am J Cardiol. 1997; 80:475-80. 


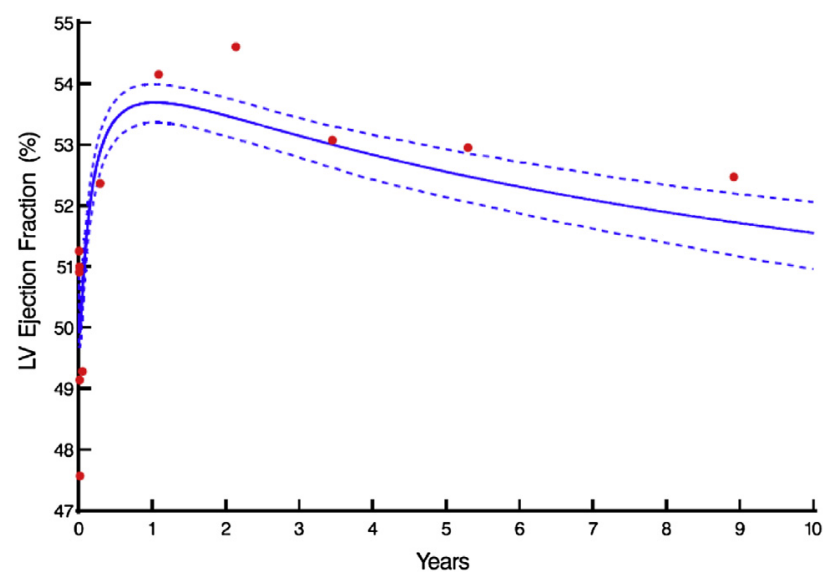

FIGURE E3. Left ventricular $(L V)$ ejection fraction after aortic valve replacement (average preoperative value, $52 \% \pm 13 \%$ ). Format same as in Figure E2.
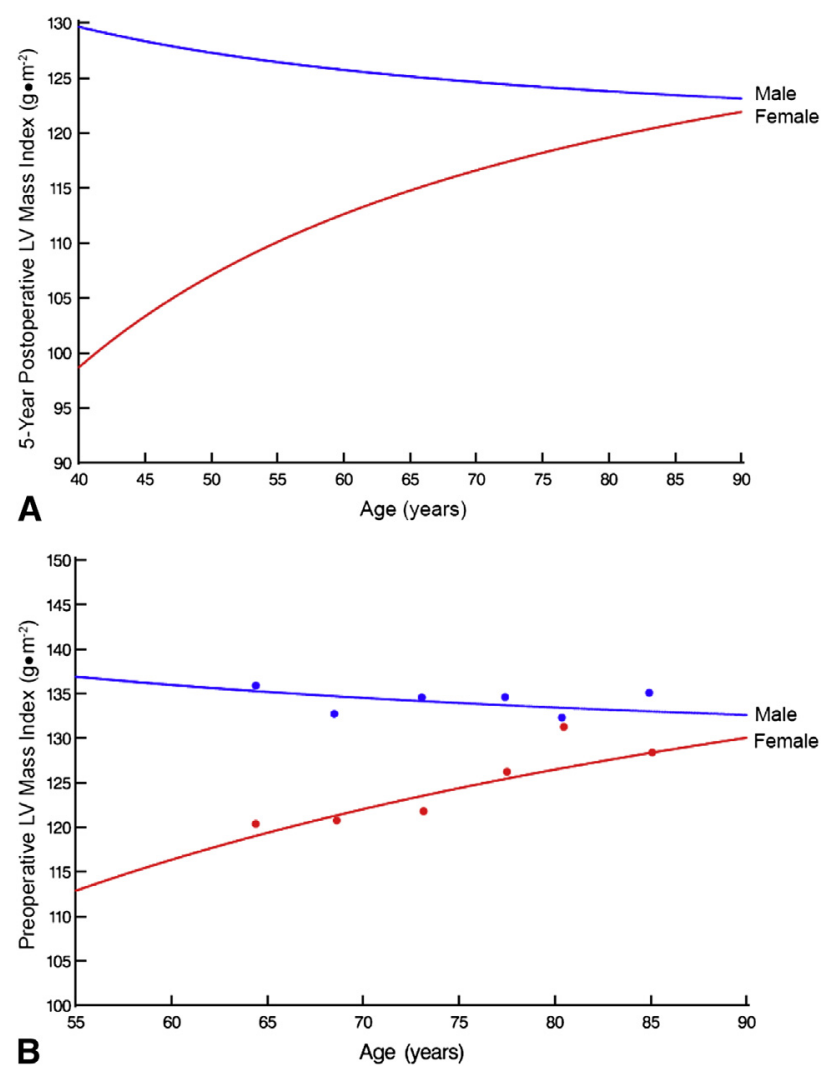

FIGURE E4. Relationship between age, gender, and left ventricular $(L V)$ hypertrophy. A, Nomogram of multivariate equation in Table 2, as described in Figure 2. B, Relationship obtained by separate linear regression for men and women. Red and blue dots represent data grouped (without regard to repeated measurements) within time frames to provide crude verification of model fit.
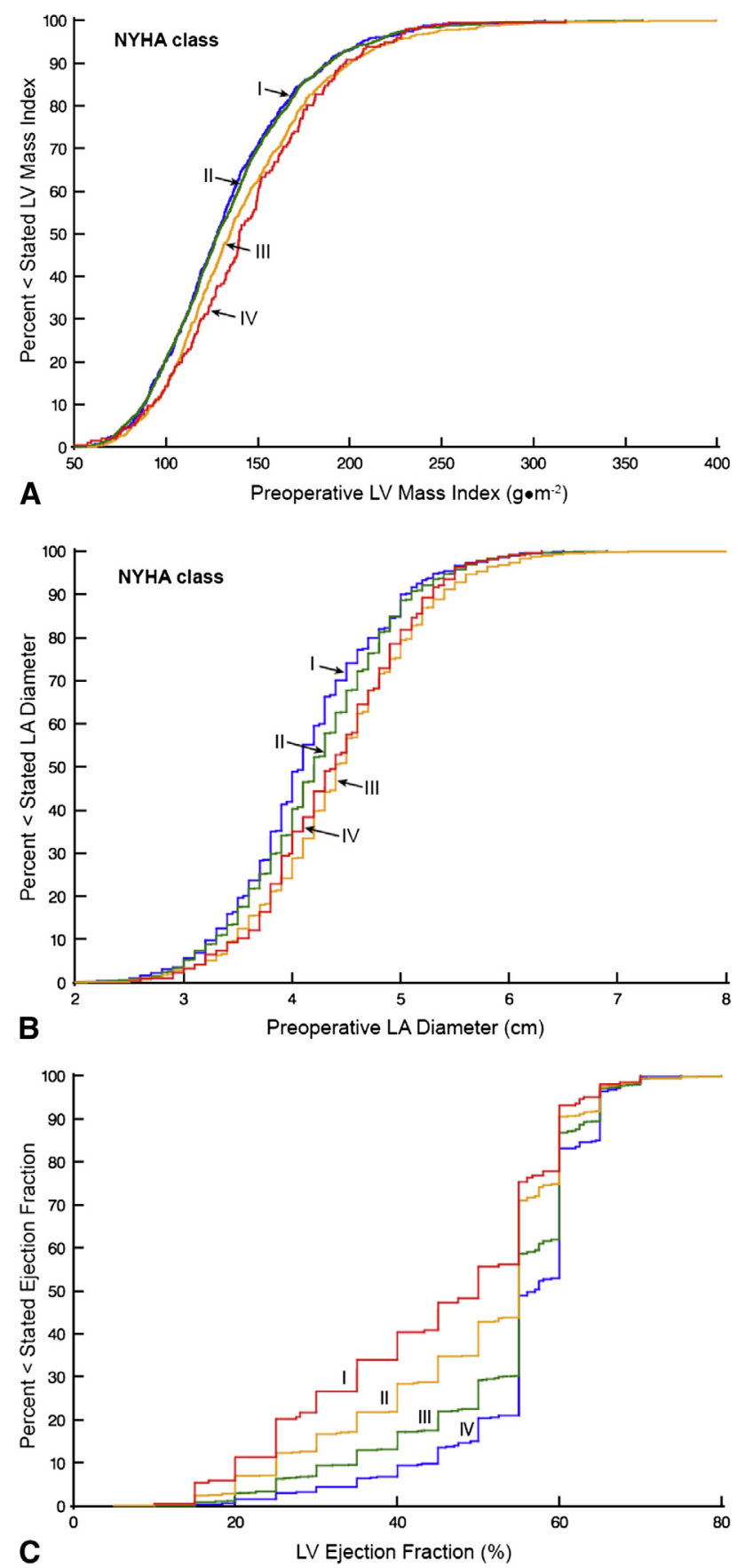

FIGURE E5. Cumulative distribution of preoperative left ventricular $(L V)$ mass index, left atrial $(L A)$ diameter, and $L V$ ejection fraction stratified by New York Heart Association (NYHA) functional class. A, LV mass index. $\mathrm{B}$, LA diameter. C, LV ejection fraction. 


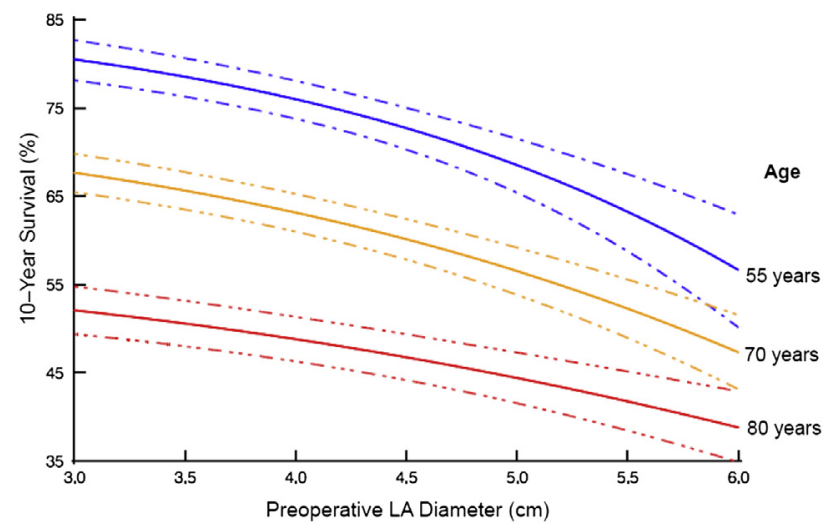

FIGURE E6. Relationship between age, preoperative left atrial $(L A)$ diameter (normal $2.7-3.8 \mathrm{~cm}$ for women and 3.0-4.0 $\mathrm{cm}$ for men), ${ }^{\mathrm{E} 2}$ and 10-year survival. Nomogram of multivariate equation given in Table E9. Values for other risk factors were set as follows: smoker who underwent surgery in January 2004, with tricuspid aortic valve, hypertension, peripheral arterial disease, left circumflex stenosis $(>0 \%)$, and New York Heart Association class I-II and without diabetes, renal disease, mitral regurgitation, left main coronary artery stenosis $(>70 \%)$, previous myocardial infarction, ventricular arrhythmia, or previous cardiac operation (body mass index, $27 \mathrm{~kg} / \mathrm{m}^{2}$; bilirubin, $0.65 \mathrm{~g} / \mathrm{dL}$; creatinine clearance, 65 $\mathrm{mg} / \mathrm{dL}$; blood urea nitrogen, $19 \mathrm{mg} / \mathrm{dL}$; hematocrit, $38 \%$; aortic orifice area, $0.7 \mathrm{~cm}^{2}$; left ventricular mass index, $135 \mathrm{~g} / \mathrm{m}^{2}$ ).

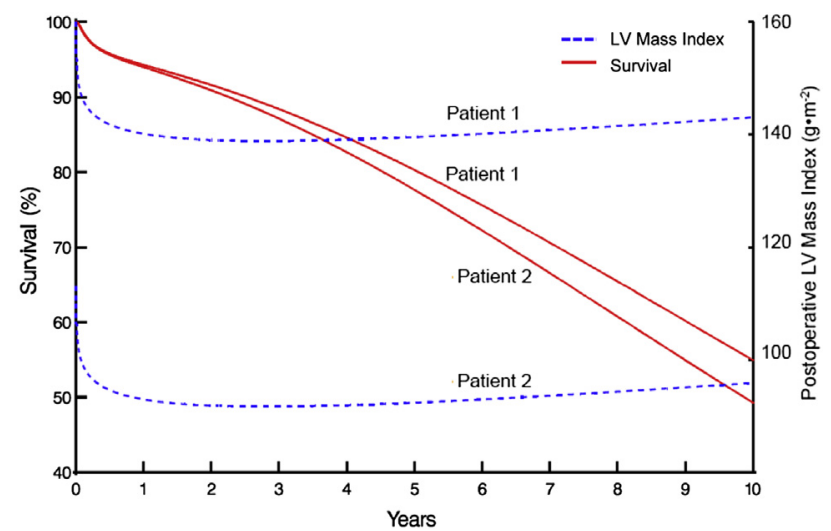

FIGURE E7. Relationship between postoperative left ventricular $(L V)$ mass index and survival in 2 hypothetical patients with otherwise identical characteristics, except for postoperative LV mass index pattern. Nomogram of univariate equation in Table E9. Each color represents patient-specific LV mass index profile similar to 15 th, 50th, and 85 th percentiles, with resultant survival in same color. Solid lines denote parametric estimates of survival; dashed lines, postoperative LV mass index.

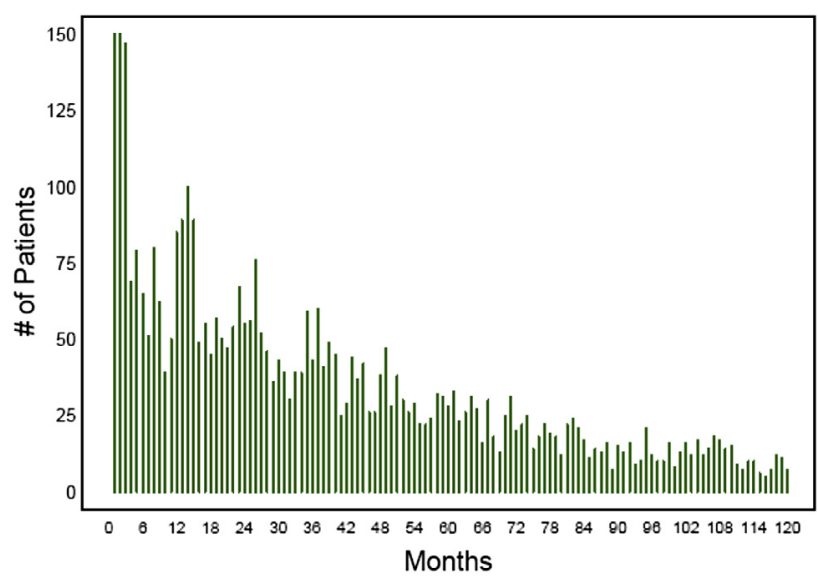

FIGURE E8. Number of patients with postoperative echocardiograms at monthly postoperative intervals. Note, yearly increases in echocardiographic measurements, suggestive of regularly scheduled follow-up examinations. 

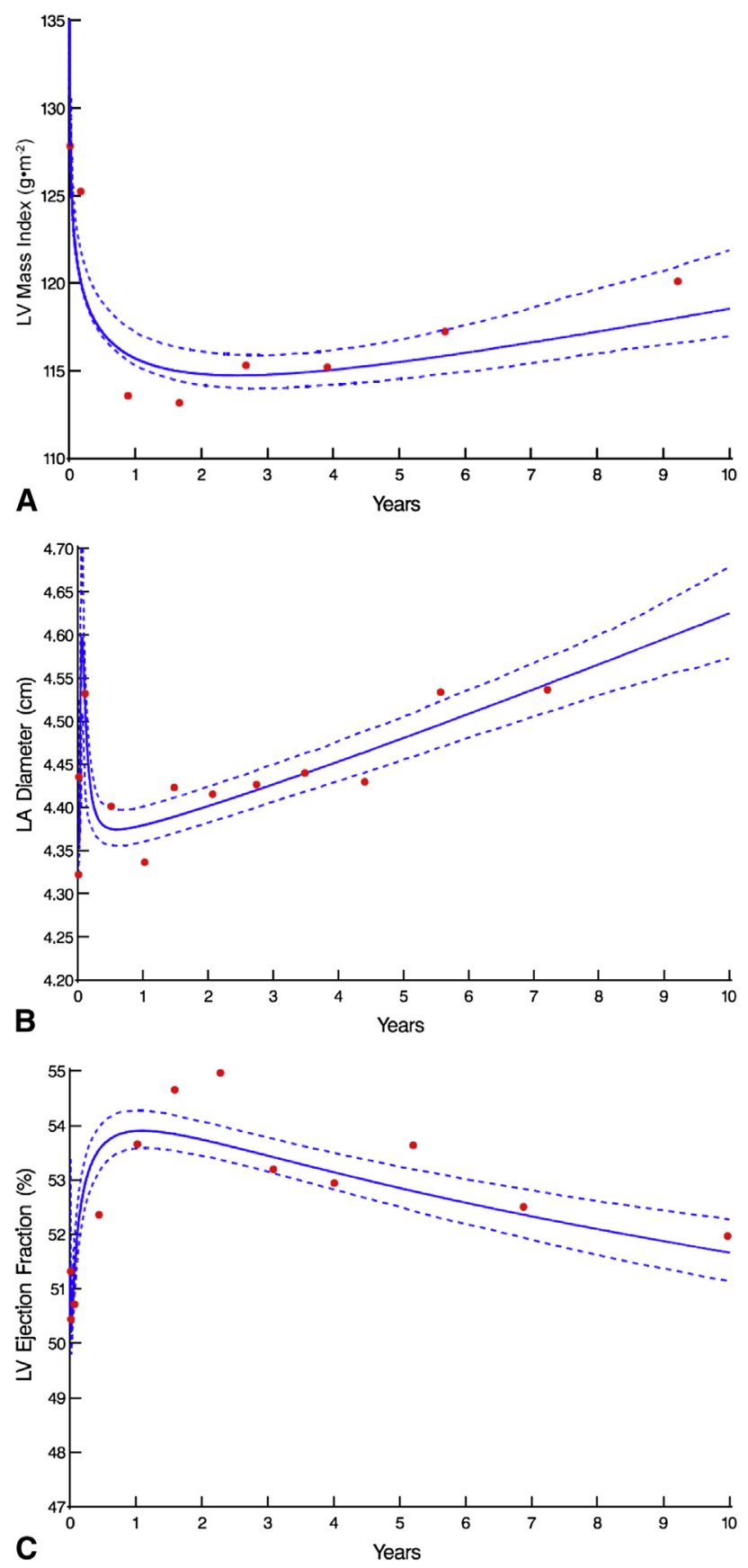

FIGURE E9. Temporal trends restricted to patients with 6 months or more of transthoracic echocardiographic (TTE) follow-up data, including all available postoperative TTEs for these patients. Solid lines represent unadjusted estimate of temporal trend enclosed within $68 \%$ bootstrap percentile confidence limits. Red circles represent data grouped (without regard to repeated measurements) within time frames to provide crude verification of model fit. A, Left ventricular $(L V)$ reverse remodeling after aortic valve replacement. B, Left atrial $(L A)$ diameter after aortic valve replacement. C, Left ventricular $(L V)$ ejection fraction after aortic valve replacement (average preoperative value, $52 \% \pm 13 \%$ ).
TABLE E1. Characteristics of aortic valve replacement (total $\mathrm{n}=\mathbf{4 2 6 4 )}$

\begin{tabular}{lcc}
\hline \multicolumn{1}{c}{ Procedure Details } & $\begin{array}{c}\text { Patients with } \\
\text { data available }\end{array}$ & Value \\
\hline Aortic prosthesis size $(\mathrm{mm})$ & 4264 & \\
19 & & $607(14)$ \\
21 & & $1280(30)$ \\
23 & & $1525(36)$ \\
25 & & $695(16)$ \\
27 & & $143(3.4)$ \\
29 & 4264 & $14(0.33)$ \\
Geometric prosthetic valve area (cm $\left.{ }^{2}\right)$ & $3.6 \pm 0.7$ \\
Normalized prosthetic valve area & 4264 & $1.8 \pm 0.33$ \\
$\quad\left(\mathrm{~cm}^{2} / \mathrm{m}^{2}\right.$ BSA) & 4264 & $-0.43 \pm 0.95$ \\
Z-value* & 4264 & $2332(55)$ \\
Coronary artery bypass grafting & 4096 & $74 \pm 32$ \\
Myocardial ischemic time (min) & 4108 & $97 \pm 37$ \\
Cardiopulmonary bypass time (min) & & \\
\hline Data presented as $\mathrm{n}(\%)$ or mean \pm standard deviation. BSA, Body surface area. $*$ Pa- \\
tient-prosthesis size expressed as standardized orifice size (number of standard devi- \\
ations by which internal orifice diameter deviated from mean normal aortic annulus \\
diameter for patient BSA). ${ }^{\text {E1 }}$
\end{tabular}

TABLE E2. Patient variables associated with larger preoperative LVMI*

\begin{tabular}{|c|c|c|c|}
\hline Variable & Coefficient $\pm \mathrm{SE}$ & $P$ value & $\begin{array}{c}\text { Reliability } \\
(\%) \dagger\end{array}$ \\
\hline Women & $0.21 \pm 0.055$ & $<.0001$ & 81 \\
\hline $\begin{array}{l}\text { Interaction }(\text { male } \times \\
\quad[\text { age } / 50])\end{array}$ & $0.19 \pm 0.042$ & $<.0001$ & 91 \\
\hline $\begin{array}{l}\text { Interaction (female } \times \\
\text { [age/50]) }\end{array}$ & $-0.17 \pm 0.067$ & .005 & 91 \\
\hline $\begin{array}{l}\text { Higher grade of aortic } \\
\text { regurgitation }\end{array}$ & $0.042 \pm 0.0041$ & $<.0001$ & 100 \\
\hline $\begin{array}{l}\text { Higher preoperative } \\
\text { AV peak gradient } \ddagger\end{array}$ & $0.16 \pm 0.013$ & $<.0001$ & 100 \\
\hline $\begin{array}{l}\text { Higher grade of mitral } \\
\text { regurgitation }\end{array}$ & $0.015 \pm 0.0054$ & .005 & 99 \\
\hline Lower ejection fraction $\S$ & $-0.17 \pm 0.012$ & $<.0001$ & 100 \\
\hline Larger LA diameter $\Phi$ & $0.21 \pm 0.020$ & $<.0001$ & 100 \\
\hline $\begin{array}{l}\text { Documented diagnosis of } \\
\text { hypertension }\end{array}$ & $0.020 \pm 0.011$ & .05 & 72 \\
\hline Complete heart block/pacer & $0.063 \pm 0.022$ & .004 & 95 \\
\hline Earlier date of surgery & $-0.016 \pm 0.0011$ & $<.0001$ & 100 \\
\hline
\end{tabular}

$L V M I$, Left ventricular mass index; $S E$, standard error; $A V$, aortic valve; $L A$, left atrial. *Logarithmic transformation of LVMI as response variable. †Percentage of times

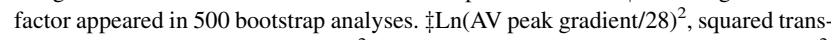
formation. $\S(\text { Ejection fraction/50 })^{2}$, squared transformation. $9(\text { LA diameter } / 5)^{2}$, squared transformation. 
TABLE E3. Preoperative risk factors associated with larger postoperative LA diameter

\begin{tabular}{lcc}
\hline \multicolumn{1}{c}{ Factor } & Coefficient \pm SE & $\begin{array}{c}\boldsymbol{P} \\
\text { value }\end{array}$ \\
\hline Overall & & \\
Larger preoperative LA diameter* & $0.18 \pm 0.012$ & $<.0001$ \\
Older age $\dagger$ & $-0.045 \pm 0.0202$ & .03 \\
Larger BMI $\dagger$ & $-0.094 \pm 0.0098$ & $<.0001$ \\
Tricuspid aortic valve & $0.019 \pm 0.0062$ & .001 \\
Higher LV systolic volume $\S$ & $0.0027 \pm 0.001$ & .03 \\
Larger septal thickness $\emptyset$ & $0.014 \pm 0.0032$ & $<.0001$ \\
Greater MV regurgitation & $0.014 \pm 0.0059$ & .02 \\
History of atrial fibrillation & $0.069 \pm 0.011$ & .03 \\
RCA stenosis $(\geq 70 \%)$ & $0.029 \pm 0.0056$ & $<.0001$ \\
Higher bilirubin $\|$ & $0.021 \pm 0.0051$ & $<.0001$ \\
Late phase & & \\
LMT stenosis $(\geq 70 \%)$ & $0.55 \pm 0.11$ & $<.0001$ \\
\hline
\end{tabular}

$L A$, Left atrial; $S E$, standard error; $B M I$, body mass index; $L V$, left ventricular; $M V$, mitral regurgitation; $R C A$, right coronary artery; $L M T$, left main trunk. *(LA diameter $/ 5)^{2}$, squared transformation. $\dagger(50 /$ age $)$, inverse transformation. $\ddagger(1 / \mathrm{BMI})$, inverse transformation. §(LV systolic volume $/ 40)^{2}$, squared transformation. $\uparrow($ Septal thickness) $)^{2}$, squared transformation. $\| \log ($ bilirubin), logarithmic transformation.

TABLE E4. Patient variables associated with larger preoperative left atrial (LA) diameter

\begin{tabular}{|c|c|c|c|}
\hline Variable & Coefficient \pm SE & $P$ value & $\begin{array}{l}\text { Reliability } \\
(\%)^{*}\end{array}$ \\
\hline Older age $\dagger$ & $0.13 \pm 0.025$ & $<.0001$ & 100 \\
\hline Larger BMI & $0.0304 \pm 0.0021$ & $<.0001$ & 100 \\
\hline $\begin{array}{l}\text { Higher grade of MV } \\
\text { regurgitation } \ddagger\end{array}$ & $0.016 \pm 0.028$ & $<.0001$ & 100 \\
\hline $\begin{array}{l}\text { Higher grade of } \mathrm{TV} \\
\text { regurgitation } \S\end{array}$ & $0.012 \pm 0.028$ & $<.0001$ & 100 \\
\hline Larger LV mass index & $0.52 \pm 0.043$ & $<.0001$ & 98 \\
\hline Larger LV systolic volume || & $-0.045 \pm 0.0086$ & $<.0001$ & 81 \\
\hline Preoperative AF & $0.37 \pm 0.051$ & $<.0001$ & 100 \\
\hline $\begin{array}{l}\text { Preoperative ventricular } \\
\text { arrhythmia }\end{array}$ & $0.15 \pm 0.038$ & $<.0001$ & 92 \\
\hline $\begin{array}{l}\text { LAD system disease }(\geq 70 \% \\
\text { stenosis })\end{array}$ & $0.096 \pm 0.027$ & .0004 & 100 \\
\hline Previous cardiac surgery & $0.21 \pm 0.032$ & $<.0001$ & 100 \\
\hline Peripheral arterial disease & $0.061 \pm 0.025$ & .02 & 52 \\
\hline Higher BUN\# & $0.14 \pm 0.030$ & $<.0001$ & 100 \\
\hline Higher bilirubin** & $0.075 \pm 0.024$ & .002 & 69 \\
\hline More recent date of surgery & $0.011 \pm 0.0029$ & .0003 & 88 \\
\hline
\end{tabular}

$A F$, Atrial fibrillation; $B M I$, body mass index; $M V$, mitral valve; $T V$, tricuspid valve $L V$, left ventricular; $L A D$, left anterior descending coronary artery; $B U N$, blood urea nitrogen. *Percentage of times factor appeared in 500 bootstrap analyses. $\dagger(\text { Age } / 50)^{2}$, squared transformation. $\ddagger \operatorname{Ln}(\mathrm{MV}$ regurgitation +1$)$, logarithmic transformation. §̧ $\mathrm{Ln}(\mathrm{TV}$ regurgitation +1$)$, logarithmic transformation. $\uparrow \mathrm{Ln}(\mathrm{LV}$ mass index), inverse transformation. $\|(40 / \mathrm{LV}$ systolic volume), inverse transformation \#Ln(BUN), logarithmic transformation. ** Ln(bilirubin), logarithmic transformation.
TABLE E5. Preoperative risk factors associated with lower postoperative LVEF

\begin{tabular}{|c|c|c|}
\hline Factor & Coefficient \pm SE & $P$ value \\
\hline \multicolumn{3}{|l|}{ Overall } \\
\hline Lower LVEF & $-0.036 \pm 0.0014$ & $<.0001$ \\
\hline Lower AV mean gradient & $0.0042 \pm 0.00068$ & $<.0001$ \\
\hline Men & $0.099 \pm 0.023$ & $<.0001$ \\
\hline Higher systolic volume index & $0.013 \pm 0.0012$ & $<.0001$ \\
\hline Previous MI & $0.12 \pm 0.025$ & $<.0001$ \\
\hline Previous cardiac surgery & $0.061 \pm 0.028$ & .03 \\
\hline Lower systolic blood pressure & $-0.0018 \pm 0.00051$ & .0006 \\
\hline History of diabetes & $0.065 \pm 0.026$ & .01 \\
\hline Higher BUN* & $-0.058 \pm 0.029$ & .05 \\
\hline \multicolumn{3}{|l|}{ Early phase } \\
\hline Older age $\dagger$ & $-0.64 \pm 0.29$ & .03 \\
\hline Greater diastolic blood pressure $\ddagger$ & $0.53 \pm 0.19$ & .008 \\
\hline \multicolumn{3}{|l|}{ Constant phase } \\
\hline Larger LA diameter $\S$ & $0.15 \pm 0.048$ & .002 \\
\hline History of smoking & $0.046 \pm 0.023$ & .05 \\
\hline
\end{tabular}

TABLE E6. Patient variables associated with lower preoperative LVEF

\begin{tabular}{lccc}
\hline \multicolumn{1}{c}{ Variable } & Coefficient \pm SE & P value & $\begin{array}{c}\text { Reliability } \\
(\%)\end{array}$ \\
\hline Male gender & $-2.4 \pm 0.37$ & $<.0001$ & 98 \\
Greater NYHA functional class & $1.3 \pm 0.22$ & $<.0001$ & 99 \\
Emergency surgery & $-13 \pm 3.9$ & .002 & 88 \\
Smaller AV orifice area $\dagger$ & $-3.5 \pm 0.63$ & $<.0001$ & 100 \\
Larger LV end-systolic volume & $0.41 \pm 0.016$ & $<.0001$ & 100 \\
$\quad$ index & & & \\
Complete heart block/pacer & $5.2 \pm 0.74$ & $<.0001$ & 100 \\
LAD stenosis (>70\%) & $2.5 \pm 0.33$ & $<.0001$ & 99 \\
Greater grade of mitral & $1.2 \pm 0.21$ & $<.0001$ & 100 \\
$\quad$ regurgitation & & & \\
Greater grade of tricuspid & $0.89 \pm 0.22$ & $<.0001$ & 100 \\
$\quad$ regurgitation & & & \\
Renal disease & $2.1 \pm 0.79$ & .008 & 98 \\
Greater BUN & $0.065 \pm 0.018$ & .0003 & 98 \\
Greater bilirubin $\ddagger$ & $1.2 \pm 0.36$ & .002 & 98 \\
History of COPD & $1.1 \pm 0.39$ & .007 & 55 \\
\hline
\end{tabular}

$L V E F$, Left ventricular ejection fraction; $S E$, standard error; $N Y H A$, New York Heart Association; $A V$, aortic valve; $L V$, left ventricular; $L A D$, left anterior descending coronary artery; $B U N$, blood urea nitrogen; $C O P D$, chronic obstructive pulmonary disease. *Percentage of times factor appeared in 500 bootstrap analyses. $\dagger \log (\mathrm{AV}$ area), logarithmic transformation. $\ddagger$ Log(bilirubin), logarithmic transformation. 
TABLE E7. Preoperative variables associated with greater postoperative AV peak gradient

\begin{tabular}{lcc}
\hline \multicolumn{1}{c}{ Factor } & Coefficient \pm SE & $P$ value \\
\hline Overall & & \\
Greater AV mean gradient* & $0.16 \pm 0.022$ & $<.0001$ \\
Greater LV mass index $\dagger$ & $0.089 \pm 0.024$ & .0003 \\
Greater LVEF $\ddagger$ & $0.049 \pm 0.0019$ & .01 \\
Smaller AV prosthesis (Z-value) & $-0.18 \pm 0.0077$ & $<.0001$ \\
Higher creatinine $§$ & $0.0014 \pm 0.00069$ & .04 \\
Absence of diabetes & $-0.053 \pm 0.016$ & .001 \\
Late phase & & \\
Younger age $\uparrow$ & $-0.43 \pm 0.056$ & $<.0001$ \\
Female & $0.45 \pm 0.095$ & $<.0001$ \\
Smaller BMI $\|$ & $-0.56 \pm 0.201$ & .005 \\
Larger AV orifice area\# & $-0.69 \pm 0.17$ & $<.0001$ \\
Higher bilirubin $* *$ & $0.201 \pm 0.079$ & .01 \\
\hline
\end{tabular}

$\overline{A V}$, Aortic valve; $S E$, standard error; $L V$, left ventricular; $L V E F$, left ventricular ejection fraction; $B M I$, body mass index. ${ }^{*} \log (\mathrm{AV}$ mean gradient), logarithmic transformation. $\nmid \log (\mathrm{LV}$ mass index $)$, logarithmic transformation. $\grave{\dagger}(\mathrm{LVEF} / 50)^{2}$, squared transformation. $\S(\text { Creatinine })^{2}$, squared transformation. $₫ \operatorname{Exp}(a g e / 50)$, exponential transformation. || $\log (\mathrm{BMI})$, logarithmic transformation. \#(1/AV orifice area), logarithmic transformation. ** ${ }^{*} \log ($ bilirubin), logarithmic transformation.
TABLE E8. Effect of postoperative LVMI on death after AVR: focused univariate analysis

\begin{tabular}{lcc}
\hline Larger postoperative $\mathbf{L V}$ mass index & Coefficient \pm SE & $\boldsymbol{P}$ value \\
\hline Early hazard phase & $0.053 \pm 0.29$ & .8 \\
Late hazard phase & $0.46 \pm 0.101$ & $<.0001$ \\
\hline
\end{tabular}

$L V M I$, Left ventricular mass index; $S E$, standard error.
TABLE E9. Incremental risk factors for death after aortic valve replacement: multivariate analysis

\begin{tabular}{|c|c|c|}
\hline Factor & Coefficient \pm SE & $P$ value \\
\hline \multicolumn{3}{|l|}{ Early hazard phase } \\
\hline Older age* & $0.37 \pm 0.14$ & .009 \\
\hline Greater NYHA functional class $\dagger$ & $0.75 \pm 0.18$ & $<.0001$ \\
\hline LMT disease $(>70 \%)$ & $0.56 \pm 0.28$ & .05 \\
\hline LCx disease $(>0 \%)$ & $0.47 \pm 0.22$ & .03 \\
\hline History of renal disease & $0.93 \pm 0.30$ & .002 \\
\hline Lower creatinine clearance $\ddagger$ & $-0.49 \pm 0.201$ & .01 \\
\hline \multicolumn{3}{|l|}{ Smaller prosthesis size } \\
\hline Z-value $\S$ & $-0.18 \pm 0.097$ & .05 \\
\hline Postoperative LV mass index & $-0.12 \pm 0.27$ & .7 \\
\hline \multicolumn{3}{|l|}{ Late hazard phase } \\
\hline Older age* & $0.64 \pm 0.081$ & $<.0001$ \\
\hline $\mathrm{AV}$ (native) orifice area & $0.25 \pm 0.23$ & .3 \\
\hline \multicolumn{3}{|l|}{ Larger LV mass index $\|$} \\
\hline \multicolumn{3}{|l|}{$\begin{array}{l}\text { Interaction: } \mathrm{LV} \text { mass index } \times \mathrm{AV} \\
\text { (native) orifice area\# }\end{array}$} \\
\hline \multicolumn{3}{|l|}{ LV dysfunction** } \\
\hline \multicolumn{3}{|l|}{ Previous MI } \\
\hline Ventricular arrhythmia & $0.29 \pm 0.11$ & .009 \\
\hline Severe MV regurgitation grade $\dagger \dagger$ & $-0.36 \pm 0.15$ & .03 \\
\hline Lower hematocrit $\ddagger \ddagger$ & $-0.53 \pm 0.15$ & .0004 \\
\hline Greater BUN & $0.014 \pm 0.0031$ & $<.0001$ \\
\hline Lower creatinine clearance $\ddagger$ & $-0.24 \pm 0.099$ & .02 \\
\hline History of smoking & $0.24 \pm 0.075$ & .001 \\
\hline Peripheral arterial disease & $0.24 \pm 0.079$ & .002 \\
\hline Insulin-dependent diabetes & $0.62 \pm 0.13$ & $<.0001$ \\
\hline Postoperative LV mass index $\S \S$ & $0.094 \pm 0.13$ & .5 \\
\hline Larger LA diameter $\boldsymbol{\Phi} \Phi$ & $0.43 \pm 0.16$ & .008 \\
\hline Z-value \|\| & $0.28 \pm 0.074$ & .001 \\
\hline Interaction (Z-value $\times$ age)\#\# & $-0.055 \pm 0.091$ & .004 \\
\hline
\end{tabular}

$S E$, Standard error; $N Y H A$, New York Heart Association; $L M T$, left main trunk; $L C x$, left circumflex coronary artery; $L V$, left ventricular; $A V$, aortic valve; $M I$, myocardial infarction; $M V$, mitral valve; $B U N$, blood urea nitrogen; $L A$, left atrial. *Exp(age/50), exponential transformation. $\dagger$ NYHA class I/II vs III/IV (0/1), binary variable.

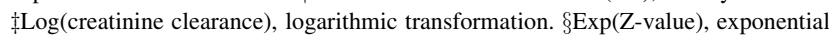
transformation. $\uparrow(\mathrm{AV} \text { orifice area })^{2}$, squared transformation. $\|(\mathrm{LV}$ mass index/ $125)^{2}$, squared transformation. \#Interaction: $(\mathrm{AV} \text { orifice area })^{2} \times(\mathrm{LV}$ mass index $/$ $125)^{2}$. ** LV dysfunction grades (none vs $>$ none), binary variable. $\dagger \dagger 1 /(\mathrm{MV}$ regurgitation +1$]$, inverse transformation. $\ddagger \ddagger(\text { Hematocrit } / 40)^{2}$, squared transformation. $\S \S$ Postoperative LV mass index/120, scaled transformation. $\mathbf{\uparrow}(\text { (LA diameter } / 5)^{2}$, squared transformation. \|\| $1 /$ (Exponential transformation of Z-value), inverse transformation. \#\#1/(Exponential transformation of Z-value) $\bullet \exp ($ age/50). 